\title{
INNOVACIÓN: LO SOCIAL LE ES INMANENTE*
}

\author{
GIOVANNI ARTURO LÓPEZ ISAZA** \\ UNIVERSIDAD TECNOLÓGICA DE PEREIRA
}

Recibido/ Received/ Recebido: 05/12/2013 - Aceptado/ Accepted / Aprovado: 16/06/2014

\begin{abstract}
Resumen
En el marco del proyecto de investigación doctoral "Emprenderismo/educación, innovación/educación, empleo/educación: lenguajes que atrapan sentidos", este documento recoge aportes sobre la innovación social, indagando con una ventana de observación 2000-2013, en las bases de información: Science Direct, Scopus, Springer Link, Google books, Google y otros actores ubicados en América y Europa. Dos conclusiones emergen de este documento: (i) El hilo conductor de los discursos sobre innovación social, indica que ella es comprendida como proceso social y como fenómeno emergente, en el contexto de prácticas ciudadanas que enfrentan problemas sociales; privilegiando intereses colectivos sobre individuales, fortaleciendo las capacidades de unos y de otros actores sociales. (ii) La educación/comunicación abre, penetra y altera mentes; le otorga sentido a la innovación, como constructo y esperanza social; con la participación/conversación de ciudadanos plurales y totales, favorece fusiones creativas que configuran innovación social.
\end{abstract}

Palabras clave: Innovación social, Educación, Emoción, Innovación, Comunicación, Aprendizaje.

\section{INNOVATION: SOCIAL ASPECT IS IMMANENT}

\begin{abstract}
In the framework of a doctoral research project "Undertaking/education, innovation/education, employment/education: languages catching senses" this document contains contributions of social innovation, looking at databases from 2000 to 2013, such as: Science direct, Scopus, Springer Link, Google books, Google and other located in America and Europe. Two conclusions came out of this document: (i) The link of social innovation speech indicates that it is understood as a social process and as an emerging phenomenon in citizen practices context facing social problems; giving priority to collective interests over individual, strengthening social actor's capacities. (ii) Education/ Communication opens, enters and disturbs minds; gives meaning to innovation as social construct and hope; with plural and total citizen's participation/conversation, encourages creative fusions that constitute social innovation.
\end{abstract}

Keywords: Social innovation, Education, Emotion, Innovation, Communication, Learning.

* Artículo de reflexión que presenta aportes sobre innovación social, resultado del proyecto de investigación doctoral "Emprenderismo/ educación, innovación/educación, empleo/educación: lenguajes que atrapan sentidos”, 2013-2014. Financiado por la Universidad Tecnológica de Pereira.

** Candidato a Doctor en Ciencias de la Educación, Área de pensamiento educativo y comunicación, Rudecolombia-Universidad Tecnológica de Pereira. Administrador de Empresas. Director del Grupo de Investigación sobre las Capacidades Tecnológicas de las Organizaciones (GICTO). Tutor del Semillero de Investigadores en Innovación en las Organizaciones (SIIO). Profesor titular de la Escuela de Tecnología Industrial. Universidad Tecnológica de Pereira - Colombia. Correo electrónico: gali@utp.edu.co,galijamj@gmail. com. Tel: +57 63137239 . Dirección postal: Escuela de Tecnología Industrial, Oficina I423 - Facultad de Tecnología, Universidad Tecnológica de Pereira, Carrera 27 \#10-02, Barrio Alamos, Risaralda. 


\title{
INOVAÇÃO: O SOCIAL LHE É IMANENTE
}

\begin{abstract}
Resumo
O presente documento, no contexto do projeto de pesquisa doutoral "Empreendedorismo/educação, inovação/educação, emprego/educação: linguagens que ganham sentidos", reúne contribuições sobre a inovação social, buscando informações nas bases de dados Science Direct, Scopus, Springer Link, Google Books, Google e outros, localizados na América e na Europa, no período de 2000 a 2013. Duas conclusões emergem deste trabalho: (i) O fio condutor dos discursos sobre inovação social indica que ela é entendida como um processo social e como fenômeno emergente no contexto de práticas cidadãs que enfrentam problemas sociais, privilegiando interesses coletivos sobre individuais, fortalecendo as capacidades de uns e de outros atores sociais. (ii) A educação/ comunicação abre, penetra e altera mentes; outorga sentido à inovação como construto e esperança social; com a participação/conversação de cidadãos plurais e totais, favorece fusões criativas que configuram inovação social.
\end{abstract}

Palavras chave: Inovação social, Educação, Emoção, Inovação, Comunicação, Aprendizagem.

López, G. (2014) Innovación: lo social le es inmanente. En: Revista de la Facultad de Ciencias Económicas de la Universidad Militar Nueva Granada. rev.fac.cienc.econ, XXII (2).

JEL: O31, I28, R58, I38.

\section{Introducción}

Según Granés $(2011,65)$ el homo sapiens se hace humano dando orden al flujo arbitrario de sensaciones que captan sus sentidos, estableciendo un aquí, un allá, un tú, un yo; dando forma estable a la siempre cambiante realidad con símbolos, imágenes, conceptos y categorías; y dando ritmo y sentido al caos de sonidos del entorno. En el presente, ese ser humano devenido en trabajador, y según Castells (2009, 61-62):

“(...) tiene como problema además de sufrir explotación en sentido tradicional, la de ser segmentado en tres categorías: aquellos que son fuente de innovación y valor, los que se limitan a obedecer instrucciones y aquellos que, desde la perspectiva de los programas de obtención de beneficios del capitalismo global, son estructuralmente irrelevantes, bien como trabajadores (sin formación suficiente, habitantes de zonas sin la infraestructura ni el entorno institucional adecua- dos para la producción global), bien como consumidores (demasiado pobres para formar parte del mercado), bien ambos. Así, la preocupación principal de una gran parte de la población mundial es evitar la irrelevancia y establecer una relación significativa, como la que se suele llamar explotación. Porque la explotación tiene sentido para el explotado. El mayor riesgo lo corren aquellos que se vuelven invisibles a los programas que controlan las redes globales de producción, distribución y valoración”.

A la par con lo anterior, se puede observar en la actualidad una oleada de campos semánticos de interpretación de la innovación con ponderación de lo social, deificando la panacea a la solución de problemas, al poderse distinguir en aquellos espacios/ tiempos, localizados en los márgenes de la sociedad, en donde ni el mercado ni el estado han llegado, experiencias significativas de seres humanos, que emergen ${ }^{1}$ a partir de situaciones de resiliencia, en las que se han encontrado tales seres, y que por efecto

\footnotetext{
Los fenómenos emergentes tienen tres características: manifiestan mucho más poder que la suma de sus partes; siempre poseen nuevas capacidades diferentes de las acciones locales que los engendraron y siempre sorprenden cuando aparecen (Wheatley \& Frieze, 2006).
} 
demostración los convierte en visibles y relevantes en el contexto de la producción, la distribución y la generación de valor, en un paisaje intelectual y económico, caracterizado por expresiones como sistema de producción de conocimientos socialmente distribuido (Gibbons et al., 1994; Gibbons, 1998), procesos de innovación socialmente distribuidos (Von Hippel, 1988) y evidencia de una explosión del conocimiento, las tecnologías, los productos y servicios, y la innovación (Sagasti, 2011), que demanda prioritariamente aprender ${ }^{2}$ de tales experiencias calificadas como de innovación social, en atención a diseñar políticas que favorezcan de forma sistemática su emergencia.

La innovación implica conocimiento y emoción. El conocimiento, como proceso, involucra disposición, con emoción ${ }^{3}$ y razón, para la interacción social, para distinguir, comunicar y comprender, dentro de un contexto cultural específico, idiosincrásico y localizado. Lo que el ser humano ve o percibe son traducciones del mundo, de una realidad, en representaciones, ideas, conceptos, teorías, lo cual implica que el conocimiento es una construcción social, ya que él ve, huele, degusta, oye, toca e interpreta, de acuerdo al medio sociocultural en el que se encuentra inmerso. Esto permite inferir que la innovación es, de suyo y en su origen, un proceso y producto social. La innovación emerge como acontecimiento colectivo de principio a fin, involucra y estimula el desarrollo de competencias a partir de la comunicación.

Sólo cuando Schumpeter $(1934,1943)$ a través de un proceso de economización y tecnologización de la innovación, la objetiva tecnológica y económica, ésta se instrumentaliza con fines de lucro, y así, y como medio de comunicación simbólicamente generalizado, se ignora su origen social y se soslayan las emociones altruistas, el desarrollo de las capacidades humanas y la utilidad social, permitiendo que domine la búsqueda de producción de patentes, licencias y demás formas de protección de propiedad intelectual $^{4}$, como código de comunicación de crecimiento económico y monetario, en detrimento de "innovaciones útiles y a la medida", que favorezcan el bienestar de los ciudadanos y de la sociedad en general, por una parte y por la otra, el predominio del concepto convencional del mundo empresarial, que privilegia el éxito frente al mero hecho creativo, cuya ideología se sustenta en el éxito en la vida a cualquier costo (Ceberio, 2009; Maidagan, Ceberio, Garagalza \& Arrizabalaga, 2009).

La innovación social se encuentra presente, cada vez con mayor frecuencia, tanto en el discurso académico como en el público. Aunque la literatura data de al menos tres décadas atrás, discusiones y publicaciones sobre el tema son cada vez más frecuentes en la actualidad.

Algunas universidades fundan en sus sedes centros de investigación sobre innovación social, fundaciones y centros privados son creados o enfocados con este propósito, y gobiernos de diferentes latitudes se comprometen a realizar actividades de fomento en este campo. Las contribuciones a la comprensión de la innovación social provienen de la sociología, la administración de empresas, la economía, el trabajo social y la ciencia política, entre otras áreas de conocimiento, que hacen que su significado sea diverso y prolífico. Este artículo presenta reflexiones a partir

2 Aprender entendido como la disposición permanente de enfrentar lo nuevo cambiando los patrones de expectación aprendidos (Luhmann \& Schorr, 1993, 104). Se trata del aprendizaje del aprendizaje, más que del aprendizaje de conocimientos.

3 "Mientras que las emociones son percepciones que se acompañan de ideas y modos de pensamiento, los sentimientos emocionales, son principalmente percepciones de lo que nuestro cuerpo hace mientras se manifiesta la emoción, junto con percepciones del estado de nuestra mente durante ese mismo periodo de tiempo(...) Las emociones son programas complejos de acciones, en amplia medida automáticos, confeccionados por la evolución. Las acciones se complementan con un programa cognitivo que incluye ciertas ideas y modos de cognición, pero el mundo de las emociones es en amplia medida un mundo de acciones que se llevan a cabo en nuestros cuerpos, desde las expresiones faciales y las posturas, hasta los cambios en las vísceras y el medio interno" (Damasio, 2010a, 175176).

4 Según Bercovitz (1994) si no se protegen los resultados de investigación a través de derechos de propiedad intelectual, ninguna empresa estará interesada en difundirlos, vía desarrollo y comercialización de los mismos, y por lo tanto no se explotarán, como tampoco beneficiarán a la sociedad. 
del trabajo investigativo que el autor del mismo se encuentra desarrollando, en el marco de doctorado en ciencias de la educación, área de pensamiento educativo y comunicación, y cuyo título es " $E m$ prenderismo/educación, innovación/educación, empleo/educación: lenguajes que atrapan sentidos". Para ello identifica un hilo conductor de los discursos sobre innovación social, provenientes de diferentes audiencias, como también una tesis/conclusión, a partir de enlaces comunicativos entre educación $e$ innovación social, como nutriente que es la primera de la segunda.

\section{Metodología}

En el desarrollo de este trabajo de investigación se indagó por los actores institucionales que en su nombre y/o misión incluyen los términos innovación social; los investigadores adscritos a ellos que realizaron investigación sobre educación e innovación social. Para la búsqueda se utilizaron los conceptos: "education social innovation research", "social innovation research", "education social innovation center" y "social innovation center", en las bases de documentos Science Direct, Scopus (en el rango 2000-2013), Springer Link, Google Books y Google; en esta última, además se buscó: "investigación educación innovación social", "investigación innovación social", "centro educación innovación social" y "centro innovación social". Se revisaron las referencias bibliográficas de los documentos examinados con el fin de identificar documentación bibliográfica relevante, la cual fue priorizada con base en el nivel de sistematización que evidenciaba. También se solicitó información a varios actores ubicados en Brasil, Canadá, Chile, Colombia, España y Francia. Asimismo, se entrevistó en forma presencial a investigadores y/o expertos en la temática en Santiago de
Chile $e^{5}$ y a través de Skype, a otros ubicados en Brasil y Estados Unidos.

Es de anotar que las bases de documentos consultadas, utilizando los conceptos en los que se incluyeron "education" y "educación", no reportaron información pertinente, lo que permite estimar que no se han realizado investigaciones con visibilidad en tales bases de datos que relacionen educación con innovación social, educación con centros de innovación social o centros de educación con innovación social. La información y documentación obtenida en la consulta a las bases de datos mencionadas y a las personas entrevistadas, sirvió para construir el trabajo aquí presentado, pues los términos "social innovation research", "social innovation center", "investigación innovación social" y "centro innovación social" dieron como salidas los insumos para construir lo que aquí se presenta. Adicional a lo anterior, se exponen reflexiones y aportes con respecto a la relación que existe entre educación $e$ innovación social.

\section{Preámbulo a una tematización de la innovación}

Como categoría de origen griego, la innovación $(\kappa \alpha \iota v o \tau o \mu \imath \alpha)$ ha significado hacer cortes nuevos, introducción de cambios en el orden establecido, introducción o adopción de nuevos comportamientos o prácticas sociales (Godin, 2011, 2012a), pero es Schumpeter (1943), quien colocó al cambio tecnológico y la innovación en el siglo XX y en el centro de la reflexión sobre el desarrollo económico, denominando al proceso de desestabilización asociado a esos cambios, temporal de destrucción creadora ${ }^{6}$. Por otra parte, la incorporación de la innovación, como elemento articulador de la movilización del

5 Para la entrevistas realizadas en Chile aproveche una pasantía realizada en el mes de mayo de 2013, en la Comisión Económica para América Latina y el Caribe - CEPAL, de las Naciones Unidas, con sede de funciones en Santiago de Chile, en la División de Desarrollo Social, en donde me reuní con la Oficial de Asuntos Sociales, Magíster en Economía, María Elisa Bernal, quien fue mi facilitadora en la pasantía. Ella fue la coordinadora del proyecto: "Experiencias en innovación social en América Latina y el Caribe", ejecutado entre el año 2004 y el 2010.

6 Es de anotar que contrario a la creencia generalizada el término tiene origen, no en Schumpeter, sino en Werner Sombart (18631941), economista que a su vez fue probablemente muy influenciado por Nietzsche. Las raíces de la destrucción creativa se remontan a la filosofía de la India, de donde la idea entró en la tradición literaria y filosófica alemana (Reiner \& Reinert, 2006; Caijaba-Santana, 2013). 
conocimiento para el desarrollo, se empezó a evidenciar cuando Sábato \& Botana (1968, 146), expresaron que "la acción de insertar la ciencia y la tecnología, como un proceso político consciente, en la trama misma del desarrollo, significa saber dónde y cómo innovar".

En el concepto propuesto por Schumpeter (1934) se incluyen sólo aquellos cambios que surgen desde adentro, de la propia dinámica del proceso y no los que le son impuestos desde afuera. Los cambios desde adentro que resultan claves para esta concepción del desarrollo económico derivan de la puesta en práctica de nuevas combinaciones. En una economía competitiva, las nuevas combinaciones implican la eliminación competitiva de las viejas y eso es lo que alimentan los temporales de destrucción creadora que pautan el desarrollo económico.

Siguiendo con Schumpeter (1934, 100-101), innovación (en alemán neuerung), es la introducción de un nuevo producto, la introducción de un nuevo método de producción, la apertura de un nuevo mercado, la apertura de una nueva fuente de materia prima, la puesta en práctica de una nueva organización en alguna industria, como por ejemplo, la creación de una posición monopólica? ${ }^{7}$.

El reduccionismo inherente a la forma en que algunos teóricos tratan los aportes de Schumpeter, desconoce la valoración que este autor le da a los aspectos sociales de la innovación. Tal desconocimiento, tanto de la valoración de los aportes de este autor como de los aspectos sociales mismos característicos de la innovación, conduce a que ella sea pensada como si fuese únicamente una prolongación de la dinámica de los mercados, derivando en una visión limitada de los acontecimientos y agentes involucrados en su eclosión y concreción, generando una epistemología de la ceguera (Ayestarán, 2011), que incorpora una sola variable axiológica y epistémica, sea ésta el sistema de precios, la externalización o subcontratación, provocando graves desviaciones y miopías en la interpretación de la innovación como fenómeno complejo, revelando lo que Ayestarán $(2011,82)$, denomina la cadena de ignorancia de los Friedman, aumentando la posibilidad de que dicha destrucción creativa de la economía convencional, como dice Santos $(2003,2009)$ se convierta en destrucción destructiva.

Ayestarán (2011) ante el reduccionismo incorporado, al evaluar la innovación del lápiz Mongol 482 fabricado por la empresa Eberhard Faber Pencil Company en los años 50 del siglo XX, considerando una sola variable axiológica y epistémica como la mano invisible de Adam Smith -el papel que juega en la generación de riqueza en las naciones y los mercados a través del sistema de precios-, por parte del Premio Nobel de Economía 1976 Milton Friedman; y la externalización o subcontratación internacional, al evaluar la innovación del ordenador portátil Inspiron $600 \mathrm{~m}$ fabricado por la empresa Dell a comienzos del siglo XXI, por parte del periodista y politólogo Thomas L. Friedman, con su teoría del aplanamiento del mundo globalizado, y las graves desviaciones y miopías que tales interpretaciones de la información y el conocimiento significan; denominó a este fenómeno como el problema de la cadena de ignorancia de los Friedman.

Teniendo en cuenta que existen asimetría y asincronicidad en la evolución de la innovación social frente a la tecnoeconómica, lo cual puede invisibilizar otras formas de innovación que redunden en nuevas maneras de creación e impacto en el mejoramiento de la calidad de vida, a continuación se exponen aportes y reflexiones relacionadas con lo social de la innovación o la innovación social.

\subsection{Project on the Intellectual History of Innovation}

En el marco de proyecto titulado Project on the Intellectual History of Innovation ${ }^{8}$, Benoit Godin del Centre Urbanisation Culture Société, del Institut National de la Recherche Scientifique (INRS), hace una investigación sobre la innovación, abordándola

Es traducción textual del alemán al español.

8 Este proyecto empezó hace unos 5 años (según respondió a través de e-mail el mismo Godin) y se pueden encontrar working papers de él, a partir del año 2008 hasta la fecha en: http://www.csiic.ca/innovation.html 
como categoría e indagando por su desarrollo histórico desde la antigüedad. Godin (2013) se plantea tres preguntas fundamentales: i) ¿Por qué la innovación adquiere un lugar central en nuestra sociedad, o dicho de otro modo, de dónde viene la idea de innovación?; ii) ¿Cómo es que la innovación llegó a ser, espontáneamente, identificada con la innovación tecnológica?; iii) ¿Cuál es la causa de que el significado del concepto de innovación, se restrinja a la innovación comercializada por la empresa? Para ello, analiza los conceptos involucrados al hablar de innovación: el cambio, la novedad, la originalidad, la invención, la creatividad, etc.; el significado de los conceptos desarrollados; los discursos construidos a nombre de la innovación; los valores involucrados en los debates con respecto a ella; las teorías y los marcos conceptuales desarrollados para explicar la innovación; el contexto en el que surgió la categoría; y la medición de la innovación.

Así, en uno de sus reportes de investigación, Godin (2012a) identifica que aunque el concepto de innovación social —en los últimos diez años-, en escritos y estudios sobre innovación, se presenta generalmente como nuevo; por lo menos en comparación con el concepto de innovación tecnológica -el cual data de la década de 1940_, el concepto de innovación social, tiene de hecho doscientos años de edad (Tabla 1). Para afirmar lo anterior, durante cinco años construye una base de datos que corresponde a un voluminoso número de documentos (la mayoría de ellos de tipo folleto), así como a fuentes documentales que cubren desde el siglo XVI en adelante, con el fin de descubrir las representaciones de la innovación social que poseen pueblos y pensadores. El reporte se circunscribe a Inglaterra, Francia y Estados Unidos. Este investigador sugiere que el concepto debe su origen al socialismo en el siglo XIX, y su resurrección en el XXI, a la innovación tecnológica. Indica tres momentos claves o de diferentes significados de innovación social a través del tiempo: socialismo, reforma social, y alternativas a las soluciones establecidas para las necesidades sociales.

Dice Godin (2012a) que el concepto de innovación social se hizo visible después de la Revolución Francesa y que significaba muchas cosas: señala que te- nía una connotación tanto positiva como negativa, y cita como ejemplo, lo escrito con referencia a la alianza entre Francia y Austria de 1756: la alianza es "una innovación social que, fue anatemizada por algunos, llamándola perturbación social, y por otros, bautizándola con el santo nombre de Progreso" (Gaillardet, 1837, en Godin, 2012a, 40).

Las dos representaciones principales de la innovación social eran el socialismo (radicalismo) y la reforma social (humanismo, igualitarismo). La asociación entre la innovación social y el socialismo se hizo primero por los propios socialistas en Francia en los años 1830 y 1840 . Pero los críticos volvieron rápidamente el concepto una categoría peyorativa, sobre todo en Inglaterra. Esto llevó a algunos a contrastar la innovación para la reforma social. De esta historia, según Godin (2012a) se podría conjeturar que tanto la innovación social como la reforma social, contribuyeron a dar legitimidad a la innovación, una palabra maldita: "(...) para una multitud de hombres el nombre de innovador, es una palabra maldita" (Considerant, 1834, en Godin, 2012a, 41). Al terminar el siglo XIX, la innovación social adquirió un tercer significado en muchos escritos, adquiriendo tal significado un atractivo creciente en el siguiente siglo: la introducción o adopción de un nuevo comportamiento o práctica social ("This month's award for the most original social innovation", en Godin, 2012a, 21).

Sin embargo, ha habido pocos usos de innovación social hasta hace poco, en comparación, por ejemplo, con la innovación en sí misma. En este sentido, la innovación social es testigo de que la innovación se perciba como positiva, en lugar de ser un factor causal en la connotación positiva de la innovación. Al igual que la innovación, la innovación social (y el innovador social), comenzó como una polémica etiqueta despectiva: el objetivo era desacreditar a alguien. Luego adquirió una connotación positiva y moral: el objetivo era alabar algo y llamar a la acción. Durante mucho tiempo, tanto las referencias positivas como negativas a la innovación social eran simples usos de frase, con pocas ocurrencias en un texto. Sólo muy recientemente se han producido escritos teóricos sobre innovación social. Lo cual comenzó con las discusiones conceptuales en los años sesenta 
Tabla 1. Innovación, innovación social: un rastreo de su origen ${ }^{9}$

\begin{tabular}{|c|c|c|c|c|c|c|}
\hline \multicolumn{7}{|c|}{ Usos de innovación* } \\
\hline & каıуотонц $\alpha$ & $\kappa \alpha \iota v о \tau о \mu \varepsilon \omega$ & 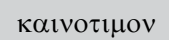 & $v \varepsilon \omega \tau \varepsilon \rho 1 \sigma \mu 1 \varsigma$ & $v \varepsilon \omega \tau \varepsilon \rho \iota \zeta \varepsilon ı \nu$ & 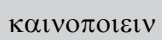 \\
\hline Aristophanes & & 3 & & & & \\
\hline Xenophon & & 5 & & & & \\
\hline Plato & 2 & 4 & & 2 & 4 & \\
\hline Aristotle & & 3 & 1 & & 6 & \\
\hline Polybius & 3 & 9 & & & 2 & 14 \\
\hline Plutarch & 16 & 10 & & 24 & 22 & 2 \\
\hline \multicolumn{7}{|c|}{ Escritores griegos sobre innovación (fechas aproximadas) } \\
\hline \multicolumn{7}{|c|}{ Aristophanes (446-386 AC) } \\
\hline \multicolumn{2}{|c|}{ Wasps } & \multicolumn{2}{|c|}{$422 \mathrm{AC}^{* *}$} & \multicolumn{2}{|c|}{ Ecclesiazusae } & $392 \mathrm{AC}$ \\
\hline \multicolumn{7}{|c|}{ Xenophon (430-355 AC) } \\
\hline \multicolumn{2}{|c|}{ Ways and means } & \multicolumn{2}{|c|}{$355 \mathrm{AC}$} & & & \\
\hline \multicolumn{7}{|c|}{ Plato (427-347 AC) } \\
\hline \multicolumn{2}{|c|}{ The Republic } & \multicolumn{2}{|c|}{$380-370$ AC } & \multicolumn{2}{|c|}{ Laws } & $350-340 \mathrm{AC}$ \\
\hline \multicolumn{7}{|c|}{ Aristotle (384-322 AC) } \\
\hline \multicolumn{2}{|c|}{ Politics } & \multicolumn{2}{|c|}{$350 \mathrm{AC}$} & & & \\
\hline \multicolumn{7}{|c|}{ Polybius (200-118 BC) } \\
\hline \multicolumn{2}{|c|}{ The History of Rome } & \multicolumn{2}{|c|}{$200-118$ AC } & & & \\
\hline \multicolumn{7}{|c|}{ Innovación DC** } \\
\hline & Francia & \multicolumn{3}{|c|}{ Inglaterra } & \multicolumn{2}{|c|}{ Italia } \\
\hline Innovation & 1297 & \multicolumn{3}{|c|}{1297} & \multicolumn{2}{|c|}{1364} \\
\hline Innovate & 1315 & \multicolumn{3}{|c|}{1322} & \multicolumn{2}{|c|}{ XIII-XIV (Innovellare) } \\
\hline Innovator & 1500 & \multicolumn{3}{|c|}{1529} & & \\
\hline & & Representac & de innovaci & través de lo & glos & \\
\hline & & & io (en las costum & establecidas) & & \\
\hline & & & Ruptura (con e & ado) & & \\
\hline & & & Utilidad & & & \\
\hline & & & mportamiento (ad & & Mercado & rcialización) \\
\hline & & & novación soc & (origen) & & \\
\hline & 1297 & & & & vvation & \\
\hline & & & & & Novateur & \\
\hline & & & & & Innovator & \\
\hline & 1803 & & & & innovation & \\
\hline & & & & 1805 & ial Innovator & \\
\hline & 1808 & & & & on sociale & \\
\hline & & & & 1832 & gateur social & \\
\hline
\end{tabular}

9 Fuente: Godin (2011, 13-25; 2012a, 16; 2012b, 23-31).

" La frecuencia corresponde a los trabajos estudiados en el working paper "Innovation and Conceptual Innovation in Ancient Greece".

** AC: antes de Cristo. DC: después de Cristo. 
y setenta, para dar paso a las teorías de los últimos años. Hoy en día, se observa la misma diversidad de significados que en el siglo XIX; sin embargo, los significados son exclusiva y predominantemente positivos (Godin, 2012a).

\subsection{Competence Center for Social Innovation and Social Entrepreneurship}

A través de una revisión sistemática de la literatura conceptual - analizada con un enfoque narrativo ${ }^{10}$ - sobre el uso actual del concepto de innovación social, Rüede \& Lurtz (2012), del Competence Center for Social Innovation and Social Entrepreneurship, del EBS Business School, de la Universität für Wirtschaft und Recht, en el marco del proyecto de investigación Social Innovations in Germany, a partir de la pregunta: ¿Qué conceptualizaciones de la innovación social existen y qué significan ellas?; examinan las conceptualizaciones más destacadas sobre innovación social, teniendo en cuenta el cumplimiento de criterios de claridad conceptual. El estudio consideró 318 documentos compuestos por artículos, reportes, libros y capítulos de libros, sobre innovación social.

Rüede \& Lurtz (2012), identificaron patrones de distinción de conceptualizaciones que son usados homogéneamente dentro de una comunidad, elementos clave, y características esenciales de innovación social, lo cual les permitió establecer siete categorías, las cuales se presentan en la Tabla 2 (Anexos). Con respecto a tales categorías, Bestuzhev-Lada (1991) y Franz (2010) citados por Rüede \& Lurtz (2012) señalan que lo social en la innovación social, podría implicar diversas comprensiones: la categoría 1 representa principalmente un conocimiento socialmente deseable de carácter social; mientras que la categoría 2 representa una comprensión sociológica, destacando nuevas formas de cómo los seres humanos organizan sus interacciones sociales; la categoría 4 también hace hincapié en el aspecto de la organización, pero que se aplica en un sentido más estrecho con el entorno laboral; la categoría 3 puede ser vista como una mezcla de las categorías 1 y 2 , porque en ella la comprensión socialmente deseada es combinada con el cambio en las interacciones sociales, en favor de los miembros desfavorecidos y socialmente excluidos de la sociedad; la comprensión de lo social en la categoría 6 se basa en el tema general de la obra social; en tanto que la categoría 5 explícitamente utiliza la categoría no-tecnológica como social; y la categoría 7 transporta a una comprensión de conectado digitalmente de lo social.

Otro punto interesante encontrado por los investigadores, es la relación de innovaciones sociales con las innovaciones con fines de lucro: la categoría 1 permite que las innovaciones sociales sean con ánimo de lucro, aunque el balance debe privilegiar el beneficio social más que al privado. Representantes de la categoría 2 negarían que las innovaciones sociales puedan ser con fines de lucro, pero prefieren subrayar que las innovaciones con fines de lucro pueden ser la causa o la consecuencia de innovaciones sociales que cambian las prácticas sociales. En la categoría 4 la eficiencia funciona como el principal motor de las innovaciones sociales, lo que significa que se espera que las innovaciones sociales paguen. La categoría 3 es comparativamente escéptica acerca de innovaciones con fines de lucro y son las que más se oponen a ellas, debido a la suposición de que el ánimo de lucro socava la construcción de comunidad y de desarrollo. La categoría 6 es también escéptica sobre el afán de lucro, pero ve a los objetivos de eficiencia como conductores de la necesidad de prestar atención a las innovaciones sociales. Debido a la orientación comercial global en las categorías 5 y 7, las innovaciones sociales dentro de tales categorías forman parte del proceso de innovación orientada al beneficio - en gran parte-global.

Estos investigadores plantean la cuestión relativa a la relación entre las innovaciones sociales y tecnológicas en las categorías construidas: las innovaciones sociales donde la tecnología contribuye al mejoramiento humano, son definitivamente posibles en la categoría 1. En la categoría 2 -al igual que las innovaciones con fines de lucro-, las innovaciones sociales sólo pueden ser la causa o la consecuencia de las inno-

10 Proceso de síntesis de estudios primarios y exploración de la heterogeneidad descriptiva, más que estadística (Petticrew \& Roberts, 2006). 
vaciones tecnológicas. En la categoría 3 las innovaciones tecnológicas no son convencionales para el desarrollo urbano. Mientras que las innovaciones tecnológicas relacionadas con la organización del trabajo son posibles en la categoría 4. En la categoría 5 los aspectos tecnológicos y sociales son distintos, pero ambos contribuyen al proceso de innovación total. La categoría 6 consideraría las innovaciones tecnológicas que contribuyan a una mejor disposición de trabajo social, como innovaciones sociales. Debido al contexto digital, las innovaciones tecnológicas y sociales se superponen en la categoría 7.

En atención a que la literatura actual sobre innovación social carece, según Rüede \& Lurtz (2012) de una revisión sistemática del concepto, su investigación constituye un avance hacia la estructuración del campo, cartografiando las diferentes conceptualizaciones de innovaciones sociales basadas en una revisión de la literatura e independiente de una disciplina de investigación específica. Ellos identifican que hay diferentes discursos sobre el concepto de innovación social, que tienen su origen en audiencias de diferentes disciplinas. De forma similar a lo identificado por Nicholls (2010, citado por Rüede \& Lurtz (2012, 29), con respecto del emprendimiento social, encontraron que el concepto de innovación social, es uno que carece de epistemología clara y donde el consenso paradigmático (refiriendo a Kuhn, 1962) aún no se ha logrado. Por lo tanto, recomiendan adoptar precauciones al citar y hacer referencia a la literatura de innovación social, sin prestar atención a un conocimiento potencialmente diferente de la innovación social en el contexto de la fuente original. Teniendo en cuenta los diferentes elementos analizados en el estudio, la confusión que evidenciaron les permite afirmar que tal desarreglo se vuelve especialmente relevante para distinguir: el entendimiento político y normativo socialmente deseable de la innovación social, como se encuentra en la categoría 1 y de la comprensión sociológica de la innovación social, presente en la categoría 2.

El estudio reveló percepciones sobre lo bien que las conceptualizaciones existentes y prominentemente utilizadas, cumplen con criterios de claridad conceptual. En general, Rüede \& Lurtz (2012) ven la innovación social como una construcción sombrilla, que después de una fase de entusiasmo, se enfrenta ahora a retos de validez por estar en riesgo de tener muchos y diversos significados para diferentes personas. Muestran que la necesidad de una mayor precisión sobre la amplitud y profundidad de definición, así como las condiciones de alcance, son un tema común a través de las definiciones en las que se enfocaron. A partir de las siete diferentes definiciones de innovación social identificadas en las siete categorías, se concentran en cuatro, que son las más mencionadas de acuerdo a su estudio y que se encuentran en las categorías 1 a 4 .

Siguiendo principalmente a Suddaby (2010), en su comprensión de claridad conceptual, construyen la caracterización que se presenta en la Tabla 3 (Anexos). Así, resaltan que es distinto hablar de claridad conceptual y de validez conceptual, la cual se acerca más a cuestiones empíricas de medición y operacionalización de variables, y utilizan las definiciones mencionadas en la Tabla 2 como mejor proxy para representar la categoría general.

Sus recomendaciones para la futura investigación se refieren al llamado general para declaraciones más específicas acerca de la amplitud, la profundidad, las condiciones de alcance, las relaciones semánticas, y la coherencia lógica del concepto. A este respecto, expresan que también debe haber una toma de conciencia de qué elementos son fundamentales para el concepto (parte de la definición, necesario que se cumplan) y qué elementos están en el contexto del concepto (no parte de la definición, regularidades empíricas asociados).

Por otra parte, identifican que en particular, es necesario un posicionamiento explícito hacia los aspectos normativos y las cuestiones de poder. Los asuntos de poder están relacionados con el debate sobre la normatividad, porque allí está la fuerza para especificar, por ejemplo, ¿cuáles son las necesidades básicas y qué es justo? Además, las diferentes conceptualizaciones de innovación social también difieren en cuanto a su ambición de cambiar las estructuras de poder existentes. Mientras que la categoría 1 utiliza la analogía empoderar: luchando contra la marginalización; y la categoría 4 incluso articula: servir a los desposeídos y confrontar los enfoques elitistas; las 


\begin{tabular}{|c|c|c|c|}
\hline 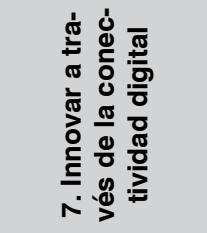 & 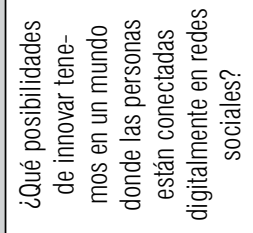 & 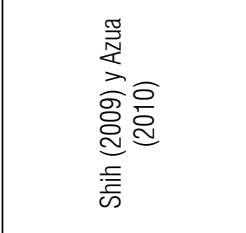 & 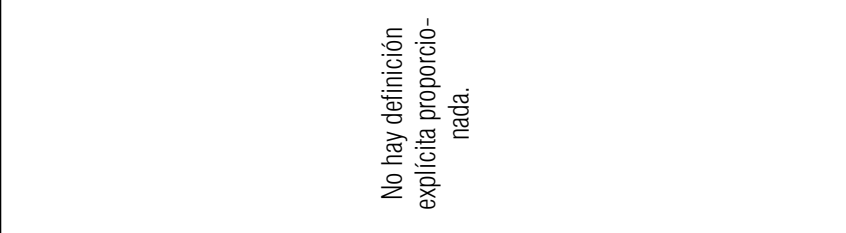 \\
\hline 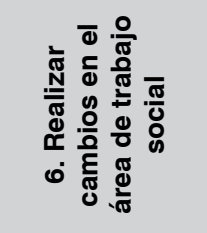 & 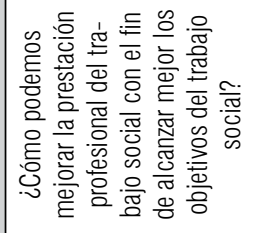 & 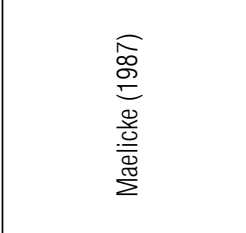 & 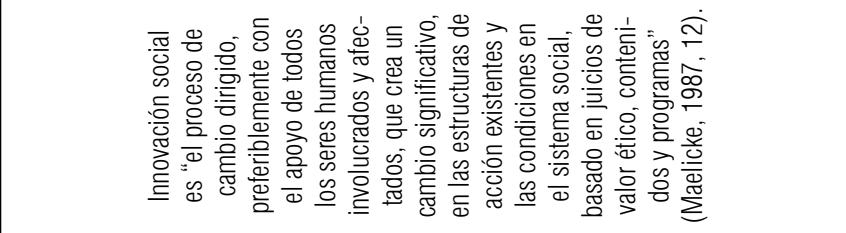 \\
\hline 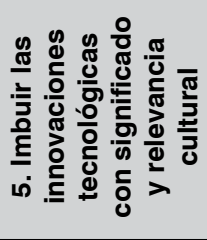 & 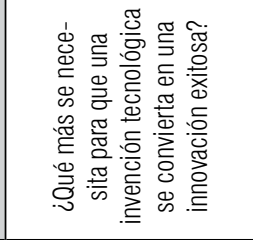 & 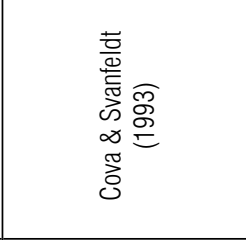 & 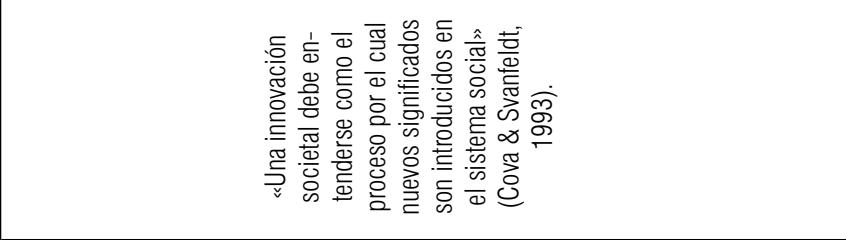 \\
\hline 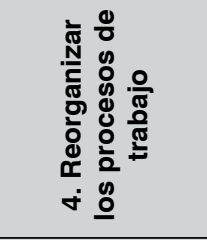 & 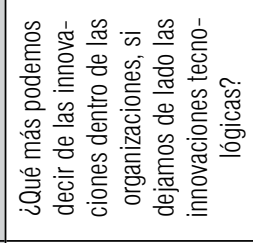 & 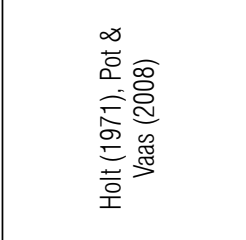 & 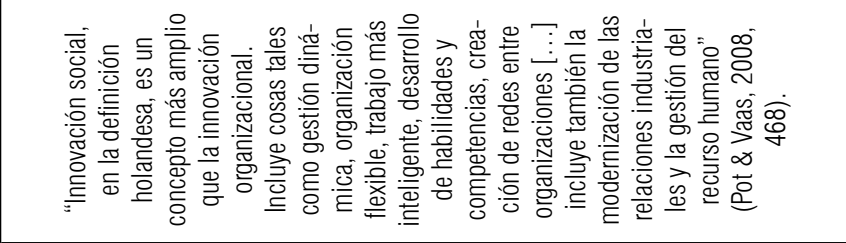 \\
\hline 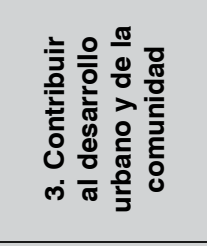 & 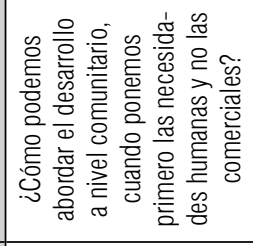 & 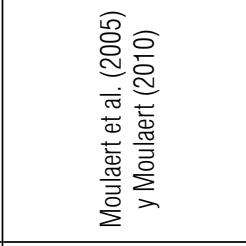 & 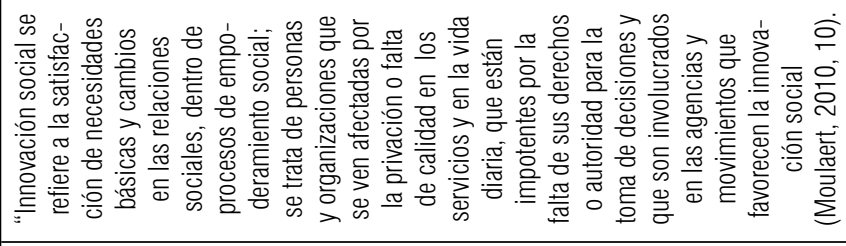 \\
\hline 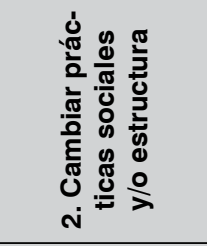 & 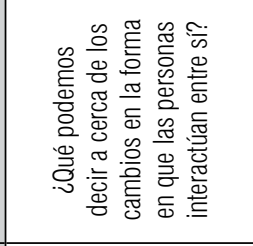 & 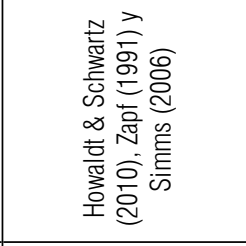 & 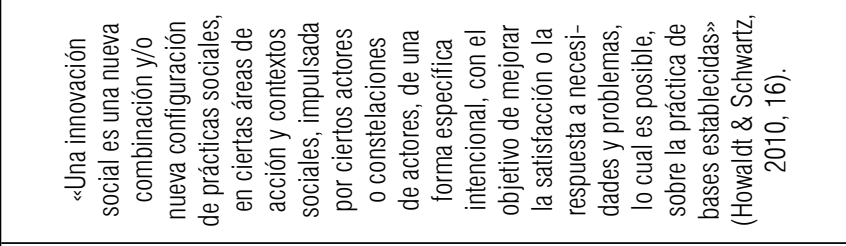 \\
\hline 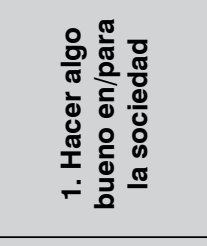 & 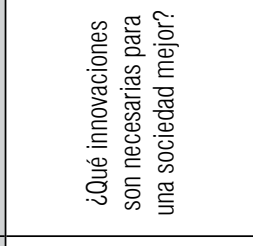 & 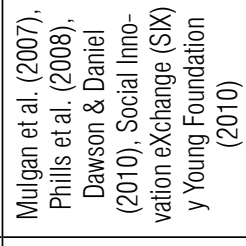 & 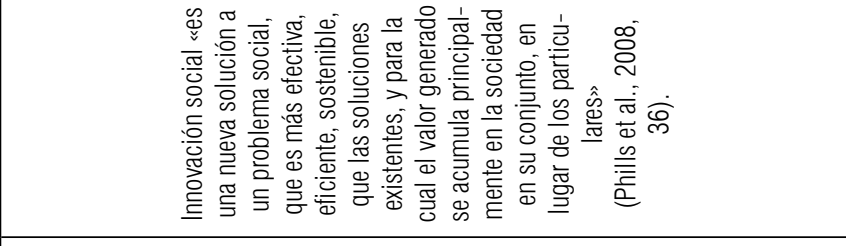 \\
\hline 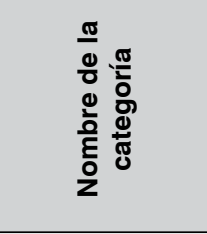 & 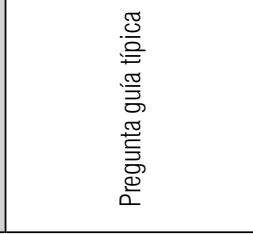 & 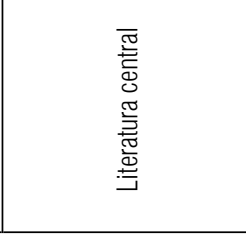 & 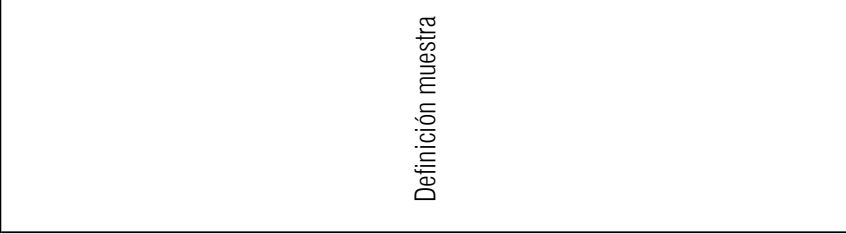 \\
\hline
\end{tabular}




\begin{tabular}{|c|c|c|c|c|c|c|c|c|c|}
\hline 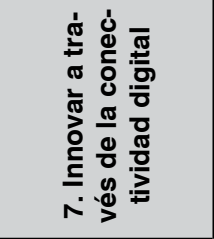 & 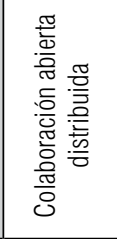 & 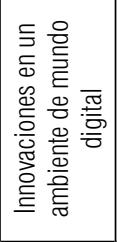 & 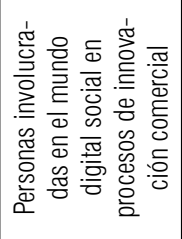 & $\sim$ & 2o & 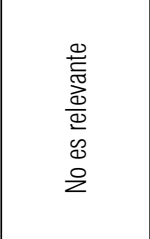 & 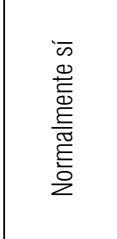 & 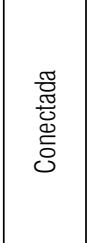 & \\
\hline 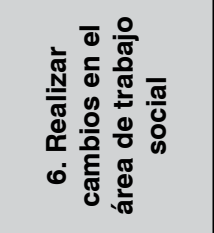 & 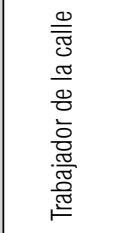 & 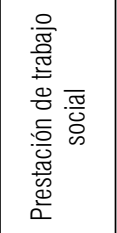 & 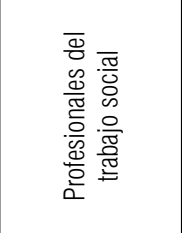 & $\infty$ & is & 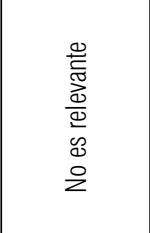 & 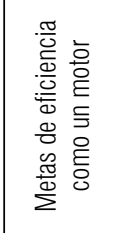 & $\frac{\frac{0}{0}}{\frac{0}{80}}$ & \\
\hline 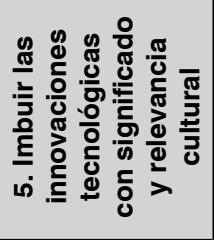 & 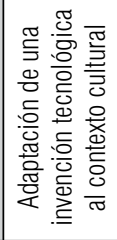 & 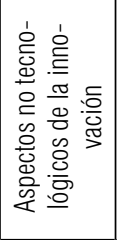 & 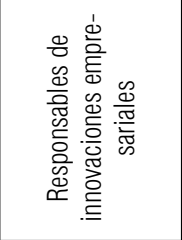 & $\mp$ & 운 & 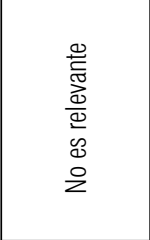 & 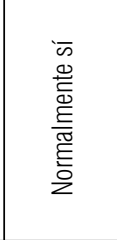 & 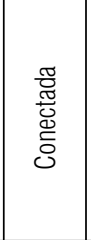 & \\
\hline 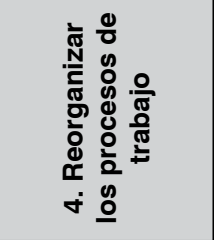 & 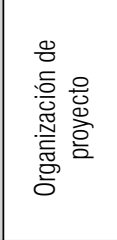 & 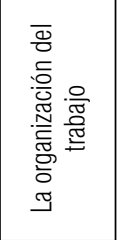 & 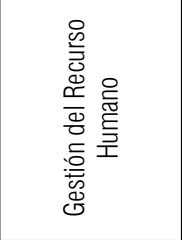 & $\stackrel{\sim}{\sim}$ & 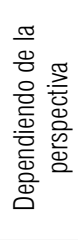 & 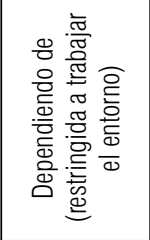 & 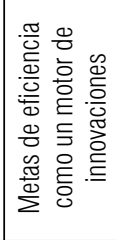 & $\frac{\frac{d}{0}}{\frac{0}{0}}$ & \\
\hline 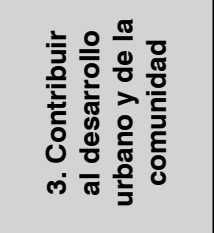 & 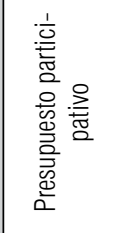 & 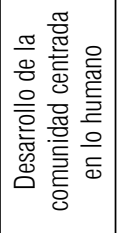 & 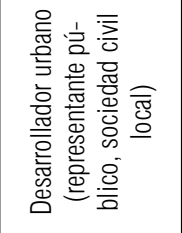 & ి్ల & is & 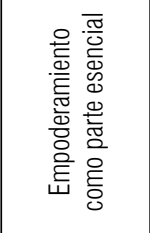 & $\begin{array}{l}\text { 䓂 } \\
\text { 党 }\end{array}$ & 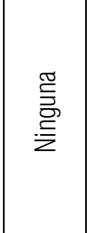 & \\
\hline 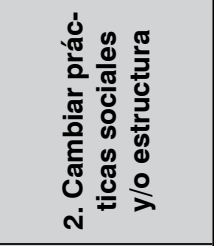 & 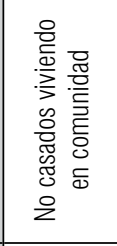 & 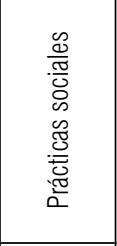 & 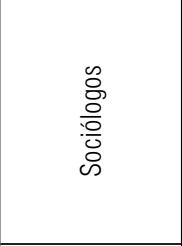 & లై & 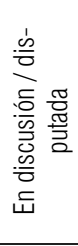 & $\begin{array}{l}\frac{\bar{w}}{\bar{E}} \\
\frac{\vec{w}}{2}\end{array}$ & 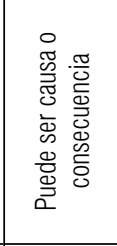 & 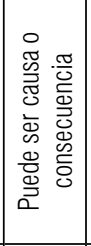 & \\
\hline 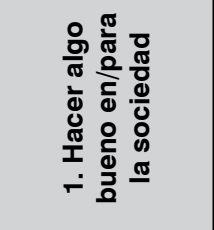 & 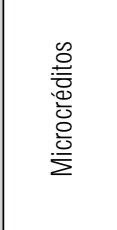 & 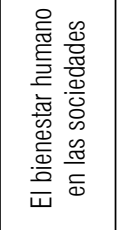 & 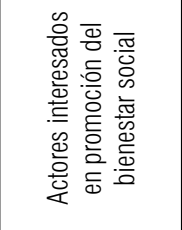 & $\underset{\simeq}{\simeq}$ & ఉ & 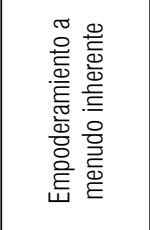 & 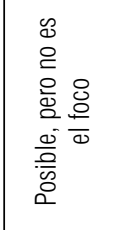 & $\frac{\frac{0}{0}}{\frac{0}{0}}$ & \\
\hline 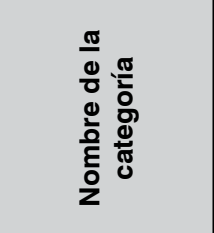 & 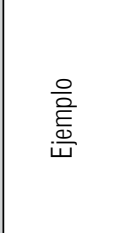 & 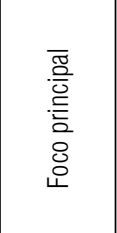 & 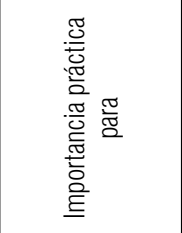 & 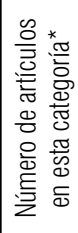 & 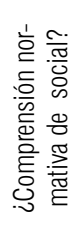 & 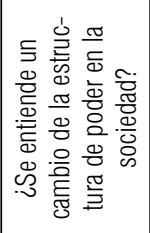 & 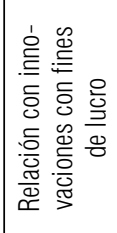 & 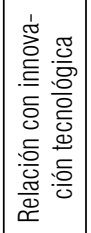 & 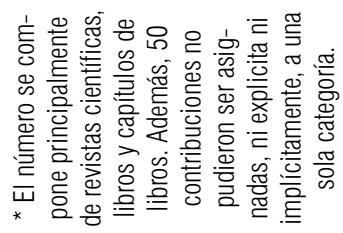 \\
\hline
\end{tabular}

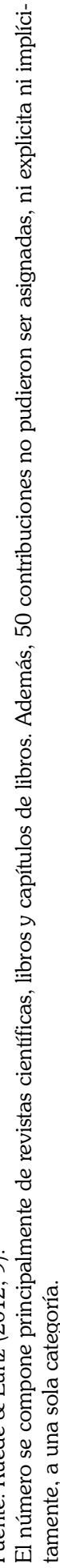


Tabla 3. Claridad conceptual de la categoría general ${ }^{2}$

\begin{tabular}{|c|c|c|c|c|}
\hline $\begin{array}{l}\text { Nombre de la } \\
\text { categoría }\end{array}$ & $\begin{array}{l}\text { Hacer algo bue- } \\
\text { no en/para la } \\
\text { sociedad }\end{array}$ & $\begin{array}{l}\text { Cambiar prácticas so- } \\
\text { ciales y/o estructura }\end{array}$ & $\begin{array}{l}\text { Contribuir al desarrollo } \\
\text { urbano y de la comunidad }\end{array}$ & $\begin{array}{c}\text { Reorganizar los procesos } \\
\text { de trabajo }\end{array}$ \\
\hline Definición muestra & $\begin{array}{l}\text { Innovación social «es } \\
\text { una nueva solución a } \\
\text { un problema social, } \\
\text { que es más efectiva, } \\
\text { eficiente, sostenible, } \\
\text { que las soluciones } \\
\text { existentes, y para la } \\
\text { cual el valor generado } \\
\text { se acumula principal- } \\
\text { mente en la sociedad } \\
\text { en su conjunto, en } \\
\text { lugar de los particu- } \\
\text { lares» } \\
\text { (Phills et al., 2008, } \\
\text { 36). }\end{array}$ & $\begin{array}{l}\text { «Una innovación social es una } \\
\text { nueva combinación y/o nueva } \\
\text { configuración de prácticas } \\
\text { sociales, en ciertas áreas de } \\
\text { acción y contextos sociales, } \\
\text { impulsada por ciertos actores } \\
\text { o constelaciones de actores, } \\
\text { de una forma específica } \\
\text { intencional, con el objetivo } \\
\text { de mejorar la satisfacción o } \\
\text { la respuesta a necesidades y } \\
\text { problemas, lo cual es posible, } \\
\text { sobre la práctica de bases } \\
\text { establecidas» (Howaldt \& } \\
\text { Schwartz, 2010, 16). }\end{array}$ & $\begin{array}{l}\text { «Innovación social se refiere a la } \\
\text { satisfacción de necesidades bá- } \\
\text { sicas y cambios en las relaciones } \\
\text { sociales, dentro de procesos de } \\
\text { empoderamiento social; se trata } \\
\text { de personas y organizaciones que } \\
\text { se ven afectadas por la privación o } \\
\text { falta de calidad en los servicios y } \\
\text { en la vida diaria, que están impo- } \\
\text { tentes por la falta de sus derechos } \\
\text { o autoridad para la toma de deci- } \\
\text { siones y que son involucrados en } \\
\text { las agencias y movimientos que } \\
\text { favorecen la innovación social» } \\
\text { (Moulaert, 2010, 10). }\end{array}$ & $\begin{array}{l}\text { «Innovación social en la definición } \\
\text { holandesa es un concepto más } \\
\text { amplio que la innovación organi- } \\
\text { zacional. Incluye cosas tales como } \\
\text { gestión dinámica, organización } \\
\text { flexible, trabajo más inteligen- } \\
\text { te, desarrollo de habilidades y } \\
\text { competencias, creación de redes } \\
\text { entre organizaciones [...] incluye } \\
\text { también la modernización de las } \\
\text { relaciones industriales y la gestión } \\
\text { del recurso humano» } \\
\text { (Pot \&Vaas, 2008, 468). }\end{array}$ \\
\hline $\begin{array}{c}\text { Definición (precisa y } \\
\text { parsimoniosa relativa } \\
\text { a amplitud y profun- } \\
\text { didad) }\end{array}$ & $\begin{array}{l}\text { «Una nueva solución» } \\
\text { como unidad de } \\
\text { análisis es muy amplia, } \\
\text { no precisa sobre cómo } \\
\text { se tratan los conflictos } \\
\text { entre «efectiva, efi- } \\
\text { ciente, sostenible, o a } \\
\text { penas». }\end{array}$ & $\begin{array}{l}\text { No precisa a) Cómo determi- } \\
\text { nar necesidades y problemas } \\
\text { que deben ser abordados, y } \\
\text { b) Cómo determinar qué es } \\
\text { mejor (nuevo vs prácticas } \\
\text { establecidas) independiente } \\
\text { de juicios individuales. }\end{array}$ & $\begin{array}{l}\text { Amplitud no clara debido a incer- } \\
\text { tidumbre de cuál es la unidad de } \\
\text { análisis; requiere el cumplimiento } \\
\text { simultáneo de «satisfacción de } \\
\text { necesidades básicas», «cambio en } \\
\text { las relaciones sociales», «empode- } \\
\text { ramiento»; circularidad en la inno- } \\
\text { vación social [...] y movimientos a } \\
\text { favor de la innovación social. }\end{array}$ & $\begin{array}{c}\text { No se mencionan propiedades y } \\
\text { características esenciales, en vez } \\
\text { de recogida de los fenómenos que } \\
\text { se supone contienen tales carac- } \\
\text { terísticas. }\end{array}$ \\
\hline $\begin{array}{l}\text { Condiciones de } \\
\text { alcance (espacio, } \\
\text { tiempo, valores) }\end{array}$ & $\begin{array}{l}\text { Concerniente al espa- } \\
\text { cio: sin limitaciones; } \\
\text { al tiempo: sin limita- } \\
\text { ciones; a los valores: } \\
\text { se prefiere creación de } \\
\text { valor para comunida- } \\
\text { des sobre creación de } \\
\text { valor para individuos. }\end{array}$ & $\begin{array}{l}\text { Concerniente al espacio: sin } \\
\text { limitaciones; al tiempo: sin } \\
\text { limitaciones; a los valores: } \\
\text { confuso. }\end{array}$ & $\begin{array}{l}\text { Concerniente al espacio: preferen- } \\
\text { cia por localidad acotada frente a } \\
\text { enfoque global sin límites; al tiem- } \\
\text { po: sin limitaciones; a los valores: } \\
\text { preferencia de la subsidiaridad y la } \\
\text { autodeterminación. }\end{array}$ & $\begin{array}{l}\text { Concerniente al espacio: confinado } \\
\text { al contexto organizacional; al tiem- } \\
\text { po: sin limitaciones; a los valores: } \\
\text { depende, p. ej. Mejora de eficacia y } \\
\text { calidad de trabajo al mismo tiempo. }\end{array}$ \\
\hline $\begin{array}{l}\text { Relaciones semán- } \\
\text { ticas (conexión con } \\
\text { otros conceptos) }\end{array}$ & $\begin{array}{l}\text { Emprendimiento social, } \\
\text { empresa social, valor } \\
\text { social, innovación, } \\
\text { social, cambio social, } \\
\text { falla de mercado. }\end{array}$ & $\begin{array}{l}\text { Cambio social, innovación } \\
\text { empresarial/socio-técnica/ } \\
\text { técnica/tecnológica, reforma, } \\
\text { modernización societal, inven- } \\
\text { ción social, hecho social, } \\
\text { innovación. }\end{array}$ & $\begin{array}{c}\text { Desarrollo urbano/comunitario, } \\
\text { barrios (vecindarios), movimientos } \\
\text { sociales, cambio social, gobierno } \\
\text { (local/comunitario). }\end{array}$ & $\begin{array}{l}\text { Innovación (producto/proceso/ } \\
\text { organizacional/ tecnológica/no- } \\
\text { tecnológica/administrativa). }\end{array}$ \\
\hline $\begin{array}{l}\text { Coherencia (de } \\
\text { los aspectos antes } \\
\text { mencionados y en } \\
\text { relación con los argu- } \\
\text { mentos teóricos) }\end{array}$ & $\begin{array}{l}\text { Inconsistencia: a } \\
\text { menudo, categorías de } \\
\text { productos tales como } \\
\text { microcréditos, son } \\
\text { Ilamadas innovaciones } \\
\text { sociales, implicando } \\
\text { que los microcréditos } \\
\text { son per se innova- } \\
\text { ciones sociales, sin } \\
\text { importar si ellos crean } \\
\text { valor social; necesidad } \\
\text { de integración en } \\
\text { teorías específicas. }\end{array}$ & $\begin{array}{l}\text { Innovación social como parte } \\
\text { de una teoría de la innovación } \\
\text { socio-tecnológica; tener el } \\
\text { "objetivo de la mejor satis- } \\
\text { facción", no significa que } \\
\text { las nuevas prácticas sociales } \\
\text { puedan continuar con y } \\
\text { realizar esta intención. }\end{array}$ & $\begin{array}{c}\text { Se basa en teorías filosóficas, } \\
\text { como el enfoque de capacidades } \\
\text { de Sen y contribuye a las teorías } \\
\text { de desarrollo urbano, tales como } \\
\text { la Teoría de la Regulación espe- } \\
\text { cializada y la Teoría del Régimen } \\
\text { Urbano (también Moulaert et al., } \\
\text { 2007). }\end{array}$ & $\begin{array}{c}\text { Concepto de innovación social } \\
\text { potencialmente reemplazado por el } \\
\text { concepto de innovación en el lugar } \\
\text { de trabajo (Pot, 2011). }\end{array}$ \\
\hline
\end{tabular}

12 Fuente: Rüede \& Lurtz (2012, 27). 
otras categorías permanecen, ya sea en silencio o en relación neutral, en cuanto a su perspectiva sobre la estructura de poder existente.

Por último, aunque Rüede \& Lurtz (2012), no están a favor de una definición específica, sugieren llegar a un acuerdo sobre dos concepciones diferentes de innovación social, que son diferentes entre sí y tienen el potencial para ser de utilidad para otras investigaciones científicas. De esta forma, asistidos por Hirsch \& Levin (1999, citados por Suddaby, 2010), Rüede $\&$ Lurtz presentan tres posibilidades diferentes para la etapa final de un ciclo de vida de los conceptos: un consenso coherente, un consenso en no estar de acuerdo, y la desaparición.

Siguiendo esta lógica, aconsejan un consenso en no estar de acuerdo y argumentar a favor de dos concepciones diferentes, a saber: una normativa y una sociológica. La conceptualización normativa se puede construir sobre el trabajo actual de las categorías 1 y 3 , la conceptualización sociológica tiene sus raíces en la categoría 2 . En términos de la conceptualización normativa, ellos ven el enfoque de capacidades de Sen (que ya se utiliza en la categoría 3), como uno de los anclajes filosóficos más adecuados. Asimismo, sugieren ver también a Yujuico (2008) y a Ziegler (2010), para conceptualizar el emprendimiento social en esta dirección. En términos de la conceptualización sociológica, recomiendan concentrarse en los cambios en las prácticas sociales, independientemente de su evaluación normativa, evitando cualquier vínculo con la noción de la mejor.

\subsection{Centre de recherche sur les innovations sociales}

Creado en 1986, el Centro de Investigaciones sobre las Innovaciones Sociales (Centre de Recherche sur les Innovations Sociales - CRISES) ${ }^{13}$, se encuentra integrado por representantes de antropología, geo- grafía, historia, matemáticas, filosofía, relaciones industriales, ciencias de la gestión, ciencias económicas, ciencias políticas, sociología y trabajo social, quienes estudian y analizan las innovaciones y las transformaciones sociales a partir de tres ejes de investigación complementarios (CRISES, 2013):

- Primer eje: innovaciones sociales, desarrollo y territorio, que comprende: regulación, acuerdos organizacionales $e$ institucionales, actores socioeconómicos, desarrollo de las colectividades, organizaciones, redes de actores, sistemas de innovación, gobernanza, colectividades y territorios, entre otros.

- Segundo eje: innovaciones sociales y condición de vida, que incluye: consumo, empleo del tiempo, ambiente familiar, inserción, hábitat, ingresos, salud, seguridad, políticas públicas, movimientos sociales, servicios colectivos, resistencia, luchas populares, entre otros.

- Tercer eje: innovaciones sociales en el trabajo y el empleo, que implica: organización del trabajo, empleo, gobernanza de las empresas, economía del saber, sindicatos, estrategias de los protagonistas, cooperación, capacitación, entre otros.

CRISES (2013) define la innovación social como:

Una intervención de los protagonistas sociales, en respuesta a una aspiración, con el objetivo de satisfacer una necesidad, de aportar una solución o de aprovechar una oportunidad para modificar las relaciones sociales, transformar un marco de acción o proponer nuevas orientaciones culturales.

Según este centro, al combinarse, las innovaciones pueden tener un impacto social a largo plazo, que supere el contexto del proyecto inicial (empresas,

13 Es una organización interuniversitaria y pluridisciplinaria, con sede central en el campus de la Universidad de Quebec en Montreal (UQAM), que agrupa alrededor de sesenta investigadores, afiliados principalmente a siete instituciones: la Université du Québec à Montréal (UQAM), la Université du Québec en Outaouais (UQO), la Université du Québec à Rimouski (UQAR), la Université Laval, la Université Concordia, la École des hautes études commerciales de Montréal (HEC Montréal) y el Institut national de la recherche scientifique Urbanisation, Culture et Société (INRS-UCS). 
asociaciones, etc.) y represente un cuestionamiento de los grandes equilibrios de la sociedad; convirtiéndose de esta forma en una fuente de transformaciones sociales, contribuyendo a la vez al surgimiento de nuevos modelos de desarrollo.

Los objetivos que orientan sus proyectos de investigación son: producir y difundir los nuevos conocimientos relativos a las innovaciones y transformaciones sociales; proporcionar un lugar de concertación y coordinación para las actividades de investigación; favorecer el surgimiento de nuevas pistas de investigación fundamental y aplicada; desarrollar nuevas asociaciones; organizar actividades científicas y de transferencia de conocimientos y capacitar a jóvenes investigadores.

Muchos de estos trabajos de investigación se llevan a cabo conjuntamente con actores socioeconómicos, como por ejemplo empresas de economía social. La publicación de los resultados de tales investigaciones se divulgan a través de colecciones como: estudios teóricos, que comprende textos conceptuales y de reflexión sobre temas específicos; estudios de caso de empresas de economía social, que son estudios empíricos; movimientos sociales, que corresponde a estudios de caso sobre la acción de los diferentes grupos sociales; tesis y disertaciones, que son los trabajos seleccionados por miembros de CRISES; número especial, que corresponde a las actas de investigación y actas de congreso; e internacional, la cual contiene los estudios publicados conjuntamente con el laboratorio de sociología de la evolución de las instituciones (CNRS).

Los miembros de CRISES cumplen un papel central en el desarrollo de redes de contacto con la sociedad civil y contribuyen activamente con las actividades de transferencia de conocimientos hacia la comunidad.

\subsection{Instituto de Innovación Social}

A partir de una trayectoria de investigación y formación en responsabilidad social de la empresa y el emprendimiento social, el Instituto de Innovación Social, de la Escuela Superior de Administración y Dirección de Empresas (ESADE), de la Universidad Ramón Llull, de Barcelona; puso en marcha en 2011: la Antena de Innovación Social, con un informe que buscaba servir de fuente de inspiración y concienciar sobre el potencial de innovación social, así como detectar los cambios y tendencias de este sector, el cual, según tal informe, se encuentra en plena expansión en todo el mundo (Goodman \& Murillo, 2011; Buckland \& Murillo, 2013).

Este primer informe, de carácter introductorio, reflexionaba sobre los debates centrales en torno a las definiciones y características de la innovación social, así como los desafíos que deben afrontar los emprendedores sociales y el contexto social en el que trabajan. En él se abordaba a la innovación social, como un término genérico que "engloba el emprendimiento social, la empresa social, la filantropía y una serie de iniciativas, sobre todo privadas, que tratan de aportar soluciones a problemas sociales urgentes todavía sin solución” (Goodman \& Murillo, 2011, 5).

En un segundo informe, publicado por el señalado Instituto de Innovación Social, Buckland \& Murillo (2013), a partir de algunos rasgos distintivos de los emprendedores sociales y de los desafíos que tienen por delante, presentan cinco variables tendientes a analizar con mayor profundidad la innovación social y para participar en el debate mundial en torno a ella: qué significa, dónde están sus límites, cómo se mide su impacto y cuáles son los factores clave del éxito de una iniciativa determinada. Dichas variables comprenden aspectos como: el nivel de transformación social logrado, hasta las estrategias utilizadas para trabajar en todos los sectores y fronteras, la estabilidad y viabilidad financieras, el tipo de innovación adoptada y la posibilidad de escalar o replicar la iniciativa (Tabla 4).

Con la convicción que "no hay una única definición de innovación social ni nunca la habrá", Buckland \& Murillo $(2013,6)$, parten de lo que entienden como urgencias en el contexto más inmediato:

"Se necesitan iniciativas probadas, testadas y que funcionen, que aporten algún tipo de impacto social —local o global-medible, que estén bien gestionadas, que sean eficientes y orientadas a resultados, que crucen sectores y modos de gestión (pública, privada, sin áni- 
Tabla 4. Cinco variables para analizar la innovación social'14

\begin{tabular}{|c|c|l|}
\hline No. & \multicolumn{1}{|c|}{ Variable } & \multicolumn{1}{c|}{ Preguntas que plantea } \\
\hline 1 & Impacto y transformación social & ¿Hasta qué punto la iniciativa logra la transformación social deseada y resuelve el problema abordado? \\
\hline 2 & Colaboración intersectorial & $\begin{array}{l}\text { ¿Quiénes son los primeros interesados en que la iniciativa tenga éxito y de qué mecanismos dispo- } \\
\text { nen? }\end{array}$ \\
\hline 3 & $\begin{array}{l}\text { Sostenibilidad económica } \\
\text { y viabilidad a largo plazo }\end{array}$ & $\begin{array}{l}\text { ¿Cómo se financia la iniciativa y qué estrategias se han adoptado para garantizar su supervivencia } \\
\text { en el futuro? }\end{array}$ \\
\hline 4 & Tipo de innovación & $\begin{array}{l}\text { ¿Es una innovación cerrada o abierta? (puede ser replicada por otros) ¿Se basa en algún concepto } \\
\text { anterior? ¿Qué rasgos innovadores presenta? }\end{array}$ \\
\hline 5 & Escalabilidad y replicabilidad & $\begin{array}{l}\text { ¿En qué medida la iniciativa se puede ampliar o multiplicar? ¿En qué condiciones se puede replicar } \\
\text { en una situación diferente? }\end{array}$ \\
\hline
\end{tabular}

mo de lucro) para coger de cada una de estas esferas lo que más les convenga. Que sean iniciativas abiertas, replicables y, al menos hasta cierto punto, escalables, es decir que sean transmisibles: que se pueda enseñar, compartir y aprender del análisis de su funcionamiento más allá de una realidad local y concreta. Y como algo particularmente relevante, conforme a la coyuntura económica que actualmente se vive, que sean iniciativas autosuficientes, que se alejen de la dependencia y del aura que los poderes públicos ejercen sobre las iniciativas sociales $y$, desde una perspectiva financiera, que sean autónomas del presupuesto público".

Estos investigadores validan las cinco variables presentadas en la Tabla 4, como parámetros útiles para analizar cualquier iniciativa, a través de cuatro ejemplos derivados de la diversidad de tipos de innovación social existentes en la actualidad (Tabla 5).

Los casos elegidos hacen referencia a la comunidad de activistas online más grande del mundo: una red local de redes que intercambian bienes y servicios sin utilizar dinero, un banco de alimentos especializado en recuperar alimentos no comercializados y redistribuirlos a personas necesitadas, y un organismo del gobierno del Reino Unido que tiene como misión aplicar las finanzas conductuales a las políticas públicas para lograr el bienestar social. Para esta valida- ción adoptan un método cualitativo sistemático basado en entrevistas semiestructuradas a un pequeño grupo de personas clave de cada organización. Se busca siempre entrevistar personalmente a los fundadores de cada iniciativa, complementando las entrevistas con un repaso de la documentación interna, páginas web, informes financieros y otras publicaciones, así como artículos e informes acerca de cada caso, realizados por entidades externas.

En el informe, Buckland \& Murillo (2013, 113-162) identifican que:

- Con respecto a las cinco variables seleccionadas y validadas, estas se pueden utilizar como parámetros para trazar una ruta hacia una innovación social efectiva. Estas plantean una serie de preguntas clave para los profesionales, grupos de la sociedad civil, gobiernos, donantes y académicos: ¿cuál es el posible impacto social de la iniciativa y cómo se puede medir? ¿La iniciativa es financieramente viable a largo plazo? ¿Quiénes son los distintos actores y cómo se implican? ¿Qué tipo de innovación se utiliza? ¿Qué posibilidades hay de escalar la innovación? Llaman la atención sobre que estas variables no se deben utilizar de ningún modo como modelo restrictivo, ya que por definición la innovación social está creando constantemente nuevos paradigmas, rompiendo barreras y aniquilando las viejas ideas y supuestos.

14 Fuente: Buckland \& Murillo $(2013,161)$. 
Tabla 5. Resumen de cuatro ejemplos de innovación social utilizados para validar las cinco variables para analizar la innovación social15

\begin{tabular}{|c|c|c|c|c|}
\hline Iniciativa & Misión & Mecanismo & Fundada & Escala \\
\hline Avaaz & $\begin{array}{c}\text { Organizar a ciudadanos de todas } \\
\text { las naciones para alcanzar un } \\
\text { mundo mejor. }\end{array}$ & $\begin{array}{c}\text { Plataforma en Internet, con oficinas en } \\
18 \text { países }\end{array}$ & $\begin{array}{c}\text { Global, con 15 millones de } \\
\text { miembros de 194 países. }\end{array}$ \\
\hline $\begin{array}{c}\text { Banc dels Aliments de } \\
\text { Barcelona }\end{array}$ & $\begin{array}{c}\text { Luchar contra la pobreza y el } \\
\text { despilfarro de alimentos. }\end{array}$ & $\begin{array}{c}\text { Recogida y redistribución de alimentos, } \\
\text { entre la población urbana desfavorecida, } \\
\text { con una campaña de recogida anual. }\end{array}$ & 1987 & $\begin{array}{c}\text { Local, moviliza a 7600 volunta- } \\
\text { rios y a } 600 \text { organizaciones de } \\
\text { toda Cataluña. }\end{array}$ \\
\hline $\begin{array}{c}\text { Behavioural Insights } \\
\text { Team }\end{array}$ & $\begin{array}{c}\text { Buscar maneras innovadoras } \\
\text { y rentables de ofrecer mejores } \\
\text { opciones a los ciudadanos. }\end{array}$ & $\begin{array}{c}\text { Organismo del gobierno del Reino Unido } \\
\text { que aplica las finanzas conductuales a las } \\
\text { políticas públicas. }\end{array}$ & $\begin{array}{c}\text { Nacional, con actividades en } \\
\text { todo el Reino Unido y con } \\
\text { posibilidad de ser replicada. }\end{array}$ \\
\hline $\begin{array}{c}\text { Redes de Intercambio } \\
\text { de Barcelona }\end{array}$ & $\begin{array}{c}\text { Intercambiar bienes y servicios, } \\
\text { y crear redes de apoyo en áreas } \\
\text { urbanas. }\end{array}$ & $\begin{array}{c}\text { Sistemas de intercambio vecinales } \\
\text { autogestionados, sin utilizar dinero. }\end{array}$ & 1992 & $\begin{array}{c}\text { Urbana, se desarrolla en ocho } \\
\text { barrios de Barcelona. }\end{array}$ \\
\hline
\end{tabular}

- El debate público en torno a la innovación social se ha prolongado durante décadas, pero que la investigación académica ha avanzado más lentamente, con apenas veinte artículos revisados por expertos y publicados antes de 2008 , que contienen innovación social o emprendimiento social, en el título. Nicholls (2009, citado por Buckland \& Murillo, 2013), identifica que esto se debe, entre otras razones, a la falta de distribuidores para la publicación de artículos sobre el tema, a la poca disponibilidad de datos fiables y, en general, al escaso interés del sector académico por un tema que, aparentemente, encuentra difuso. También encuentran que ha habido más actividad docente que investigadora, pues según un estudio elaborado por Ashoka (2007, citado por Buckland \& Murillo, 2013), ya había 250 profesores que impartían innovación social ${ }^{16}$.

- Tres oleadas de actividad académica: la primera, impulsada por Austin y Dees, se basaba en la teoría de la gestión y fue adoptada por las escuelas de negocios de Estados Unidos (19982001); la segunda, surgida en Europa, incorporaba distintas perspectivas de las ciencias sociales, con una considerable actividad de la Saïd Business School (2002-2007); y la tercera, sur- gida a partir de 2008 y que propagó la actividad de investigación en Asia, Australia y África.

- Citando a Nicholls (2009, citado por Buckland \& Murillo, 2013) señalan que la noción de innovación social también ha cambiado a lo largo de estas etapas: ha pasado de ser considerada una actividad comercial que proporciona un bien público, a concebirse como la solución de problemas sociales mediante modelos radicalmente nuevos que promueven el cambio sistémico.

- A partir de las definiciones más citadas se pueden inferir dos características esenciales de la innovación social: en primer lugar, la novedad y la efectividad de la idea y, en segundo lugar, su orientación hacia la solución de un problema social (lo que engloba retos sociales, medioambientales, económicos y éticos), que genera valor social en lugar de valor individual.

- Numerosos autores que señalan que la innovación social puede adoptar diversas formas: puede ser un producto, un proceso de producción o una solución tecnológica. Sin embargo, también puede ser una idea, un principio, un artículo de la legislación, un movimiento social,

5 Fuente: Buckland \& Murillo $(2013,161)$.

16 El informe no identifica si es en pregrado, posgrado o se trata de formación complementaria, ni tampoco el nombre del estudio elaborado por Ashoka (2007, citado por Buckland \& Murillo, 2013). 
una intervención o una combinación de todos estos factores. Mulgan et al. (2007, citado por Buckland \& Murillo, 2013), identifican que a la innovación normalmente se le dan definiciones complejas y que los autores del Oxford Saïd Business School y del Skoll Centre for Entrepreneurship de Londres, prefieren la sencilla: ideas nuevas que funcionan.

- Un gran debate en torno a la familia de términos innovación social, emprendimiento social y empresa social, con el consenso general de que se refieren a distintos aspectos de este sector emergente. El emprendimiento social se utiliza para explorar las cualidades personales de las personas a partir de una iniciativa particular, por ejemplo, el liderazgo, el pensamiento radical y la capacidad de innovar e inspirar a otros. La empresa social es el término utilizado para reflejar el modelo organizativo elegido para resolver un problema social determinado, haciendo hincapié en la consecución del doble objetivo de valor económico y social. La innovación social, a su vez, se suele considerar como de mayor alcance y más radical, por cuanto promueve un cambio sistémico.

- Además de la gran cantidad de definiciones, existe un sinfín de herramientas y mecanismos para promover la innovación social desplegada desde todo tipo de centros de innovación social, desde organismos gubernamentales hasta centros académicos, pasando por fundaciones y organizaciones que tienen la motivación de conseguir más innovación social. Sin embargo, a pesar de la riqueza y la vitalidad del sector, existe muy poco consenso en torno a cómo medir la innovación social y la forma de definir su impacto social. También hay una sorprendente falta de uniformidad en los indicadores y metodologías de los informes.

- Los problemas sociales del mundo son tan complejos y diversos que nunca habrá un único modelo válido para todos los tipos de innovación social. La propia naturaleza de la innovación social, como una forma nueva y mejor de resolver los problemas sociales, significa que ni siquiera está en el interés de sus partidarios crear definiciones o marcos fijos, sino más bien en crear los entornos para el proceso de destrucción creativa con el propósito social de prosperar. Es al definir esos entornos cuando resultan útiles las variables propuestas por Buckland \& Murillo (2013), porque ayudan a encontrar respuestas a interrogantes como: ¿Existe una estrategia para la viabilidad financiera a largo plazo? ¿Qué tipo de modelo de innovación se está adoptando (abierto o cerrado)? ¿Cuál es la relación entre los distintos sectores? ¿Hay suficiente libertad para escalar la innovación?

Finalmente, el Instituto de Innovación Social expresa en su informe la presencia de un sector en expansión, de distintos tipos de organizaciones que tiene interés en promover, apoyar y observar las innovaciones sociales de todo el mundo, destacando algunas de las organizaciones, fundaciones, centros académicos, y plataformas y comunidades participativas internacionales, que apoyan la innovación social (Tablas 6 , 7 y 8$)$.

\subsection{Social guide to social innovation}

En el contexto de la estrategia Europa 2020, la Comisión Europea publicó en marzo de 2013 la Guía Europea para la Innovación Social, elaborada a partir de experiencias de intervención social financiadas con fondos europeos. Aunque en su introducción reconoce que no hay un consenso real en cuanto al significado de innovación social, la define como:

"El desarrollo e implementación de nuevas ideas (productos, servicios y modelos), para satisfacer necesidades sociales y crear nuevas relaciones sociales o colaboraciones. Ella representa nuevas respuestas a situaciones de exigencia social, que afectan el proceso de interacciones sociales. Su objetivo es mejorar el bienestar humano. Innovaciones sociales, son innovaciones que son sociales, tanto en los fines como en sus medios, que no sólo son buenas para la sociedad sino que impulsan la capacidad de los individuos para actuar" (European Commission, 2013, 6). 
Tabla 6. Fundaciones y organizaciones ${ }^{17}$

\begin{tabular}{|c|c|c|c|c|c|c|}
\hline Nombre & Lugar & Escala & Financiación & $\begin{array}{l}\text { Red de } \\
\text { contactos }\end{array}$ & $\begin{array}{l}\text { Servicios de } \\
\text { apoyo }\end{array}$ & $\begin{array}{l}\text { Investiga- } \\
\text { ción }\end{array}$ \\
\hline Skoll Foundation & EE. UU. & Global & $x$ & $x$ & $x$ & $x$ \\
\hline Ashoka & EE. UU. & Global & $x$ & $x$ & $x$ & \\
\hline Acumen Fund & EE. UU. & Global & $x$ & $x$ & & \\
\hline Young Foundation & Reino Unido & $\begin{array}{l}\text { Reino Unido y cada vez más } \\
\text { internacional }\end{array}$ & & $x$ & $x$ & $x$ \\
\hline Schwab Foundation & EE. UU. & Global & $x$ & $x$ & $x$ & $x$ \\
\hline $\begin{array}{l}\text { Unreasonable } \\
\text { Institute }\end{array}$ & EE. UU. & Global & $x$ & $x$ & $x$ & \\
\hline Root Cause & EE. UU. & EE. UU. & & $x$ & $x$ & $x$ \\
\hline Echoing Green & EE. UU. & EE. UU. & $x$ & $x$ & $x$ & \\
\hline Centre for Social Innovation & Canadá & Canadá (especialmente, Toronto) & & $x$ & $x$ & $x$ \\
\hline
\end{tabular}

Tabla 7. Plataformas y comunidades internacionales ${ }^{18}$

\begin{tabular}{|c|c|c|c|c|c|}
\hline Nombre & Lugar & $\begin{array}{c}\text { Novedades e } \\
\text { información }\end{array}$ & $\begin{array}{c}\text { Red de con- } \\
\text { tactos }\end{array}$ & $\begin{array}{c}\text { Servicios de } \\
\text { apoyo }\end{array}$ & $\begin{array}{c}\text { Espacio de trabajo } \\
\text { compartido }\end{array}$ \\
\hline Social Innovation Exchange & Reino Unido & $x$ & $x$ & $x$ & \\
\hline Asian Social Innovation Exchange & Asia & $x$ & $x$ & $x$ & \\
\hline Australian Social Innovation Exchange & Australia & $x$ & $x$ & \\
\hline Social Innovation Europe & Europa & $x$ & $x$ & $x$ & \\
\hline Social Edge & EE. UU. & $x$ & $x$ & \\
\hline
\end{tabular}

Tabla 8. Centros académicos ${ }^{19}$

\begin{tabular}{|c|c|c|c|c|}
\hline Nombre & Lugar & Docencia & Investigación & $\begin{array}{l}\text { Formación de } \\
\text { incubadoras }\end{array}$ \\
\hline $\begin{array}{l}\text { Stanford Centre for Social Innovation de la Stanford } \\
\text { Graduate School of Business }\end{array}$ & EE. UU. & $x$ & $x$ & \\
\hline Skoll Centre de la Saïd Business School & EE. UU. & $x$ & $x$ & \\
\hline Instituto de Innovación Social de ESADE & España & $x$ & $x$ & $x$ \\
\hline Social Enterprise Initiative de Harvard & EE. UU. & $x$ & & \\
\hline Social Enterprise Knowledge Network & Latinoamérica & $x$ & $x$ & \\
\hline $\begin{array}{l}\text { Centre for Advancement of Social Entrepreneurship de } \\
\text { Duke University }\end{array}$ & EE. UU. & $x$ & $x$ & \\
\hline Centro de Innovación Social de INSEAD & Francia & $x$ & $x$ & \\
\hline Centre de Recherche sur les Innovations Sociales & Canadá & $x$ & $x$ & \\
\hline School for Social Entrepreneurs & Reino Unido, Australia, Canadá & $x$ & & $x$ \\
\hline
\end{tabular}

Fuente: Buckland \& Murillo $(2013,162)$.

Fuente: Buckland \& Murillo $(2013,162)$.

Fuente: Buckland \& Murillo (2013, 162). 
La guía da claves a las autoridades públicas para impulsar la innovación social, dado que la Comisión considera que es una estrategia esencial para la competitividad de la Unión Europea en cuestiones sanitarias, de educación, envejecimiento o cambio climático.

En la guía se sistematiza un conjunto de lecciones aprendidas, que se espera sean de utilidad para ajustar las políticas de financiación públicas en el marco de financiación europea 2014-2020. En ella se resalta la importancia de la evaluación del impacto de la innovación social para identificar las políticas, métodos y estrategias, más efectivas.

En este sentido, Innobasque ${ }^{20}$ y Sinnergiak de la UPV/EHU ${ }^{21}$, están construyendo el Índice Regional de Innovación Social (Resindex), el cual debe permitir medir la innovación social a partir de un sistema de indicadores propios, e identificar el impacto en donde se ha implementado. En su fase piloto se ha aplicado a 282 agentes de Euskadi, tanto a empresas como a centros tecnológicos, universidades y organizaciones sin ánimo de lucro (Innobasque, 2013).

En el prefacio de la guía, la Comisión Europea, reconoce que:

"La actual situación de crisis que se vive, el cambio climático, el alto grado de desempleo y sus consecuencias sociales, han propiciado el auge de la innovación social, como palanca para asegurar un desarrollo económico, social y medioambiental sostenible, que genere empleo y mantenga la calidad de vida en Europa" (European Commission, 2013, 5).
El análisis de buenas prácticas, relacionadas con innovación social, se realiza desde un enfoque inductivo, empleando como ejemplos programas reales financiados y ofreciendo recomendaciones para el desarrollo de una estrategia de innovación social para futuros programas, de acuerdo con diez pasos (Tabla 9).

\subsection{Challenge Social Innovation -CSI}

Los organizadores de la conferencia Challenge Social Innovation - $\mathrm{CSI}^{22}$-, que tuvo lugar en Viena en 2011, cien años después de que Schumpeter desarrollará su teoría económica de la innovación, vieron una oportunidad para ampliar el concepto de innovación. Su objetivo fue: establecer la innovación social como un tema principal en el trabajo y el discurso de la comunidad científica. Así, se buscó dar respuesta a preguntas como ¿Qué significa hoy en día innovación social? ¿Cómo desarrollar un modelo sostenible para la investigación en innovación social? ¿Qué pueden contribuir las ciencias humanas y socioeconómicas a la innovación social? Su producto: la llamada Declaración de Viena (Vienna Declaration, $\mathrm{VD}$ ), sobre las prioridades de investigación en innovación social, a partir de un conjunto de temas de investigación definidos previamente; así como un libro basado en los aportes de la conferencia, publicado por Springer Internacional en 2012.

En Challenge Social Innovation participaron 350 investigadores y expertos en innovación social de más de 50 países. Estuvieron grupos relativamente pequeños o más o menos establecidos en investigación sobre innovación social, un gran número de recién llegados, y algunos de los actores más relevantes en el conjunto más amplio de prácticas de innovación social, incluyendo investigadores sobre

20 Agencia Vasca de la Innovación, como estrategia de innovación social asociada al desarrollo regional.

21 Universidad del País Vasco/Euscal Herriko Unibertsitatea.

22 Organizada por el Centre for Social Innovation (ZSI) de Vienna, Austria; el Social Research Centre (sfs) de Dortmund University of Technology, de Alemania; y la Net4Society, Network of National Contact Points of the Social Sciences and Humanities, del Séptimo Programa Marco de la Comisión Europea; y en su comité directivo participaron el Center for Social Innovation (CSI), Stanford University (USA); la University of Québec at Montreal (UQAM)/Research Center on social Innovations (CRISES), de Montreal, Canadá; el Social Research Centre (sfs) of Dortmund University of Technology, Alemania; el Centre for Social Innovation (ZSI), de Vienna, Austria; el Net4Society and Research Promotion Society (FFG), de Vienna, Austria; el National Endowment for Science, Technology and the Arts (NESTA), de Londres, RU; la Charles University, de Praga; el OECD Forum on Social Innovations, Paris, Francia; y la Net4Society, Bonn, Alemania. 
Tabla 9. Diez pasos prácticos para implementar la innovación social ${ }^{23}$

\begin{tabular}{|c|c|c|}
\hline \multirow{4}{*}{$\begin{array}{l}\text { Cambiando mentes y } \\
\text { creando una estrategia } \\
\text { inteligente de } \\
\text { especialización }\end{array}$} & $\begin{array}{l}\text { Aprender sobre } \\
\text { innovación social y unir } \\
\text { piezas. }\end{array}$ & $\begin{array}{l}\text { Liderar no quiere decir asumir íntegramente la toma de decisiones sobre un programa. Las instituciones } \\
\text { públicas han de conocer el enfoque basado en la innovación social y tener la capacidad para ponerlo } \\
\text { en práctica en un contexto concreto. Para ello, se recomienda conocer la realidad y la dinámica social } \\
\text { de un territorio, implicar a agentes clave, líderes comunitarios y ponerlos en contacto con personas } \\
\text { expertas. Posteriormente, este proceso se abre al conjunto de la comunidad para debatir las mejores } \\
\text { propuestas. }\end{array}$ \\
\hline & $\begin{array}{l}\text { Definir la táctica y } \\
\text { cómo llevarla a la } \\
\text { práctica. }\end{array}$ & $\begin{array}{l}\text { Etapa dedicada al establecimiento de criterios de evaluación de las fases del programa de trabajo. Estas } \\
\text { evidencias deben ser coherentes con la lógica de la innovación y la mejora continua. Puede requerir } \\
\text { la mejora de las competencias del equipo técnico de las instituciones implicadas (p.ej. formación). }\end{array}$ \\
\hline & $\begin{array}{l}\text { Partir del conocimiento } \\
\text { en profundidad del } \\
\text { contexto. }\end{array}$ & $\begin{array}{l}\text { Se trata de anticipar las tendencias o desafíos futuros a los que se puede enfrentar la comunidad, e } \\
\text { integrar este conocimiento en el quehacer de las políticas públicas y del desarrollo socioeconómico de } \\
\text { la región. Crear un listado de potencialidades de la zona por muy pequeñas que parezcan. }\end{array}$ \\
\hline & $\begin{array}{l}\text { Priorizar y seleccionar la } \\
\text { estrategia. }\end{array}$ & $\begin{array}{l}\text { La comunidad debe asumir la innovación social como una de sus prioridades, que deben estar clara- } \\
\text { mente definidas, presupuestadas y formar parte de la agenda sociopolítica de la región. }\end{array}$ \\
\hline \multirow{4}{*}{$\begin{array}{l}\text { Acciones sobre la } \\
\text { aceleración de la } \\
\text { implementación }\end{array}$} & $\begin{array}{l}\text { Desarrollar herramientas } \\
\text { de colaboración con el } \\
\text { tejido social. }\end{array}$ & $\begin{array}{l}\text { Este apartado concentra sus esfuerzos en transmitir competencias a la ciudadanía y sus entidades para } \\
\text { apropiarse de la lógica de la innovación social, por ejemplo, aprendiendo cómo hacer sostenibles } \\
\text { sus iniciativas ciudadanas, cómo promover coaliciones comunitarias, o cómo rentabilizar socialmente } \\
\text { iniciativas de auditoría social a instituciones y empresas. }\end{array}$ \\
\hline & $\begin{array}{l}\text { Promover plataformas } \\
\text { abiertas hacia la } \\
\text { innovación. }\end{array}$ & $\begin{array}{l}\text { Parte más organizativa del plan de trabajo, dedicado a la definición compartida de una hoja de ruta } \\
\text { que oriente las actividades de los diferentes actores sociales participantes, sin perder de referencia los } \\
\text { objetivos previstos. Compartir una visión y un estilo de gobernanza son aspectos claves en esta fase. }\end{array}$ \\
\hline & $\begin{array}{l}\text { Desarrollar recursos } \\
\text { donde incubar la } \\
\text { innovación social. }\end{array}$ & $\begin{array}{l}\text { Una vez se han creado las condiciones necesarias para la financiación europea, la comunidad está } \\
\text { "preparada" para co-gestionar un proceso de innovación que incida tanto en la mejora de políticas } \\
\text { públicas, en la creación de nuevas empresas (o mejora de las existentes) y en la dinamización de la } \\
\text { participación ciudadana. }\end{array}$ \\
\hline & $\begin{array}{l}\text { Crear laboratorios e } \\
\text { infraestructuras para la } \\
\text { innovación social. }\end{array}$ & $\begin{array}{l}\text { Definido el proyecto piloto o experimental, es la parte más visible del proceso, donde se crean estruc- } \\
\text { turas, parques tecnológicos, nuevos modelos de negocio desde una nueva dinámica de participación. } \\
\text { Los campos de intervención son diversos. Puede tener impacto en la regeneración empresarial de una } \\
\text { zona, el diseño urbanístico, el impacto ambiental o en la prestación de servicios públicos más ajustados } \\
\text { a las necesidades de la población. }\end{array}$ \\
\hline \multirow{2}{*}{$\begin{array}{l}\text { Escalando a través de } \\
\text { intercambio regional y } \\
\text { cambio sistémico }\end{array}$} & $\begin{array}{l}\text { Definir la zona económica } \\
\text { de trabajo para la } \\
\text { innovación. }\end{array}$ & $\begin{array}{l}\text { Las propuestas deben asentarse como iniciativas económicas viables. Las autoridades pueden fomentar } \\
\text { modelos de negocio sostenible y de base centrada en la innovación social. Pueden crearse zonas de } \\
\text { especial protección donde laboratorios experimentales y prácticas empresariales convivan y contribuir } \\
\text { así al desarrollo social de la región. }\end{array}$ \\
\hline & $\begin{array}{l}\text { Promover un intercambio } \\
\text { internacional de prácticas } \\
\text { innovadoras en el } \\
\text { marco de los programas } \\
\text { europeos }\end{array}$ & $\begin{array}{l}\text { El éxito de estas buenas prácticas reside también en su capacidad para hacerlas evidentes y compar- } \\
\text { tirlas en el marco de otras experiencias a escala internacional. El ciclo del programa se cierra una vez } \\
\text { se pone en valor la contribución de la innovación social al conjunto del desarrollo económico y social } \\
\text { de Europa. }\end{array}$ \\
\hline
\end{tabular}

ella, provenientes de los sectores privado, público y civil de la sociedad. Los participantes coincidieron en que las altas expectativas en la praxis de la innovación social aún no se cumplen, ni son facilitadas por bases científicas, capacidades y metodologías de investigación adecuadas. Así, el gran logro de la asamblea de investigadores - con un trasfondo mul- ticultural y multidisciplinario de todos los continentes, si bien centrado principalmente en el contexto europeo-, fue muy oportuno y apropiado para dar a conocer los diferentes enfoques, y la necesidad de fomentar bases teóricas y metodológicas comunes, comparables internacionalmente, fiables y aplicables a la investigación en innovación social. Más de 150

23 Fuente: European Commission (2013). 
participantes tomaron parte en reuniones bilaterales preestablecidas, con el propósito de discutir sus propuestas de investigación para ser financiadas por el Séptimo Programa Marco Europeo (Hochgerner, Howaldt \& Schindler-Daniels, 2011).

La VD, concebida como un servicio - de la convención de estudiosos sobre innovación social reunidos en Viena-, dirigido a expertos en política de investigación e innovación de la Comisión Europea, la OCDE y la UNESCO, así como a las instituciones nacionales de políticas de investigación; presenta recomendaciones sobre lo que la Conferencia consideró necesario a ser tratado en las agendas de investigación por venir. La VD tiene en cuenta los desafíos sociales y societales ${ }^{24}$ que la Comisión Europea ha propuesto en la Estrategia Europa 2020, y al enfrentarlos habla de un nuevo paradigma de la innovación, el cual se caracteriza esencialmente por la apertura del proceso de innovación a la sociedad, además de que empresas, universidades e institutos de investigación, ciudadanos y clientes, se convierten en actores relevantes de los procesos de innovación; la innovación se convierte en un fenómeno social general y cada vez influye más en los ámbitos de la vida (Hochgerner, Franz, Howald \& Schindler-Daniels, 2011; Franz, Hochgerner \& Howaldt, 2012).

¿Cómo se produjo la VD? A las 14 sesiones temáticas de la conferencia, se les pidió que sugirieran un máximo de cuatro temas de su área temática que consideraran como las más urgentes y relevantes en la investigación sobre innovación social. Los 56 temas resultantes fueron votados por los 350 participantes, dando lugar a los 14 tópicos de investigación núcleo de la VD. Pero como la misma declaración subraya (Franz, Hochgerner \& Howaldt, 2012, 380-381):

\section{“(...) estos temas no representan la culmi-} nación del proceso de determinación de los temas de investigación, de hecho toda la operación se basa en ser lo suficientemente valiente como para iniciar el proceso $y$ llegar a la VD, y al mismo tiempo ser lo suficientemente modesto para saber que esto es sólo un comienzo, pues ella debe ser leída, comentada y considerada, como punto de partida para definir temas de investigación cruciales en ciencias sociales y humanas, con miras a la identificación, desarrollo e implementación de las innovaciones sociales más necesarias en el siglo XXI".

Los resultados del proceso vivido se resumen en dos epígrafes (Hochgerner et al., 2011; Franz, Hochgerner \& Howaldt, 2012):

El primero expresa que en general se requiere de avances científicos para cumplir con las expectativas y desarrollos en las prácticas de innovación social: elaboración de las características particulares del concepto y clarificación de definiciones; incorporación del concepto de innovación social en una teoría integral de la innovación; y desarrollo de metodologías coherentes para identificar y medir innovaciones sociales.

En el segundo se encuentran los temas de investigación priorizados:

- El potencial de la innovación social en la economía social, la sociedad civil, las empresas de negocios, y el estado.

- La gobernanza multinivel y la receptividad de los gobiernos a las innovaciones sociales.

- El papel de los procesos sociales en variados formatos de colaboración y estructuras organizacionales en la innovación empresarial.

24 El Reporte BEPA (Bureau of European Policy Advisers), distingue las innovaciones sociales de acuerdo con su ámbito de aplicación: social, societal, sistémico. Lo social, definido como: las demandas sociales que tradicionalmente no son contempladas por el mercado o las instituciones existentes y que se relacionan con los grupos más vulnerables de la sociedad; lo societal, se define como: los retos sociales en los que el límite entre lo social y lo económico es borroso o se difumina, y que se relacionan con la sociedad en su conjunto; y lo social entendido como sistémico, se define como: los cambios fundamentales en las actitudes, valores, estrategias y políticas, estructuras organizacionales y procesos, servicios y sistemas de suministro; es reestructuración de la sociedad en la dirección de un ámbito más participativo, donde el empoderamiento y el aprendizaje son fuentes del bienestar (BEPA, 2011; Hubert, 2012; Franz, Hochgerner \& Howaldt, 2012). 
- La relación entre las innovaciones de servicios y las innovaciones sociales.

- Innovaciones en el lugar de trabajo para un trabajo más inteligente y mejor.

- Creación de valor mediante innovaciones sociales y diferentes formas de medición de valor.

- Seguimiento, evaluación y medición de los recursos sociales para la innovación y el impacto social de la tecnología.

- Enfoques y competencias de las ciencias sociales para contribuir activamente a la implementación práctica de las innovaciones sociales.

- Las contribuciones distintivas del conocimiento basado en las humanidades y métodos de indagación (tiempo: historia; ideas y conceptos: filosofías y cosmovisiones; comunicación: lingüística,...) a las innovaciones sociales.

- Establecer una base empírica multinacional de prácticas promisorias para la inclusión y la integración.

- Las condiciones de participación y autogestión en las innovaciones sociales dirigidas a la superación de la pobreza y el empobrecimiento.

- Indicadores de los efectos a corto y largo plazo del sistema educativo en la calidad de vida, el bienestar, la capacidad de innovación.

- El aprendizaje permanente, el trabajo y la solidaridad intergeneracional, como componentes de envejecimiento socialmente comprometido.

- Oportunidades y riesgos de los medios sociales para permitir a gran escala y sistémicamente innovaciones sociales.

El libro Challenge Social Innovation y la VD, finalizan haciendo referencia sobre la European School of Social Innovation (ESSI). Esta escuela con sede en Viena, establecida oficialmente el 10 de octubre del 2011, con la colaboración de investigadores del
Centre for Social Innovation (ZSI) y del Social Research Center (sfs) de la Technische Universität de Dortmund; fue concebida como:

"Una red internacional de competencia, para llegar a eruditos $e$ instituciones europeas y mundiales, dedicados a la investigación en innovación social, la educación académica y la formación profesional. La ESSI comprende y coordina actividades en materia de investigación y educación, mas no se le llama una European School porque deba limitarse a los investigadores, estudiantes $e$ instituciones europeas. Por el contrario, se abre a la participación intercontinental en investigación, cursos y programas de estudio, pero con un enfoque específico sobre las condiciones y las fuentes de innovaciones sociales arraigadas en los sistemas sociales europeos" (Franz, Hochgerner \& Howaldt, 2012, 383).

Los debates de la conferencia y la priorización de los temas de investigación relacionados con innovación social, ilustraron claramente que hasta hace poco el área de innovación social ha sido virtualmente ignorada como un fenómeno independiente en la investigación socioeconómica sobre innovación, por no hablar de la investigación en las ciencias humanas: innovación social rara vez aparece como un término específico y definido, con un alcance claramente delineado. Sobre todo se utiliza como una especie de metáfora en el contexto del cambio social y técnico. Tenemos que admitir, expresan Hochgerner et al., $(2011,5)$ y Franz, Hochgerner \& Howaldt, $(2012,383)$, que la innovación social en la actualidad es un término que a casi todo el mundo le gusta, pero que todavía hace falta una definición precisa y claramente aceptada.

Se espera que la ESSI ayude a corregir esta deficiencia al reunir una comunidad internacional de investigación, facilitando una cooperación científica cada vez más prolífica, y que avance en el desarrollo de un concepto teóricamente sólido de innovación social. Termina la VD expresando: que mucho de lo anterior, dependerá de la alineación de las capacidades de las ciencias sociales y humanas, de los esfuerzos conjuntos para analizar y dar conferencias sobre 
el desarrollo de conceptos, conocimiento e investigación sobre innovación social; una petición de apoyo a la ESSI, con el objetivo de seguir desarrollando la comunidad internacional de investigadores, así como la formación académica y las organizaciones de formación profesional, en innovación social.

En noviembre de 2013, se realizó la conferencia Social frontiers: the next edge of social innovation research, con la participación de los actores que organizaron CSI, incluyendo además a la CEPAL, entre los panelistas expertos y entre los ponentes, exponentes de Colombia. La conferencia fue organizada por NESTA, TEPSIE (The theoretical, emprirical and policy foundations for building social innovations in Europe) y Glasgow Caledonian University, con el soporte de la Social Innovation Exchange, Skoll Centre for Social Entrepreneurship de Oxford y la Rockefeller Foundation. El objetivo de esta conferencia fue reunir a investigadores, que desde diferentes disciplinas, investigan sobre innovación social, para consolidar los conocimientos existentes, identificar las brechas y desarrollar una agenda política futura de investigación para la innovación social (SIRE, 2013).

\subsection{Proyecto: Experiencias en Innovación Social en América Latina y el Caribe}

El proyecto Experiencias en innovación social en América Latina y el Caribe, iniciativa derivada de la CEPAL con el apoyo de la Fundación W. K. Kellogg, tuvo como objetivo: identificar, mediante un concurso, experiencias innovadoras que se hubieran gestado en América Latina y el Caribe; evaluarlas y analizarlas en profundidad a fin de promover la réplica creativa, tanto en el país en donde nacen como en otros países de la región.

El proyecto se ejecutó en el periodo 2004 - 2010, en el que fueron implementados cinco ciclos (del 2004 al 2009) en los que se presentaron cerca de 4800 postulaciones de prácticamente toda América Latina y el Caribe, en los que a través de un proceso de selección -que incluyó una visita en el terreno-, se escogieron 72 experiencias finalistas y 25 ganadores, cubriendo las áreas de salud, educación, nutrición, juventud, generación de ingresos, desarrollo rural, responsabilidad social y voluntariado. Con respecto a las perspectivas de género y de sostenibilidad ambiental, es de resaltar que fueron considerados temas transversales que debían estar comprendidos en las áreas mencionadas.

Tal procedimiento garantizó que todas las experiencias reunieran cinco importantes cualidades: ser socialmente innovadoras y sostenibles, ser costo eficientes, tener posibilidades de ser replicadas y asegurar la verdadera participación de la comunidad o los beneficiarios (Rodríguez, Bernal \& Cuervo, 2011, 11). Para una ilustración complementaria se sugiere ver la Tabla 10 (Anexos).

La CEPAL, al tratar la innovación en el campo social, expresa que ella "siempre se refiere al conjunto de acciones necesarias para transformar una situación particular, que incluyen desde el rediseño de los procesos hasta el desarrollo de nuevas capacidades en las personas, ya que toda innovación supone una nueva competencia" (Rodríguez \& Alvarado, 2008, 35), entendiendo por competencia, "disposición subjetiva con capacidad objetiva". Engel (1997, citado por Rodríguez \& Alvarado, 2008, 29), teniendo en cuenta la importancia de la cooperación entre las empresas, al momento de crear oportunidades para la innovación, coloca el énfasis en "los actores sociales como agentes de innovación, dado el carácter múltiple, amplio, sistemático, colectivo y organizado que presentan las innovaciones en la realidad". Afirma que el "conocimiento se genera y regenera en un proceso grupal, es decir social, y que por ende, no sólo se reproducen los resultados del conocimiento, sino también los procesos necesarios para reproducirlo". Para que este conocimiento se "produzca, asimile y difunda" es necesario "la articulación de los diferentes agentes que participan en la generación y difusión del conocimiento". Tal articulación sería la "forma orgánica, débil y difusa, en que tendría lugar el diálogo necesario entre los diversos tipos de conocimiento - científico, técnico, vivencial-, que sobre determinan cada salto innovador, en un proceso que se encadena y ramifica con otras prácticas". Asimismo, Engel (1997) concibe la innovación como el resultado de la interacción comunicativa entre actores sociales que realizan determinadas prácticas relevantes. Finalmente, el mismo Engel (1997) advierte que el conocimiento es socialmente construido, embebi- 
do en las dinámicas sociales de una organización, una comunidad o un grupo.

Engel (1997, 130-134) considera la innovación esencialmente como un proceso de aprendizaje social, incorporado e interrelacionado intrínsecamente a la evolución continua de una práctica ${ }^{25}$. La capacidad de innovar no puede considerarse como una destreza individual, ni tampoco como la suma de una serie de aptitudes individuales: debe tomarse como una competencia social compartida por los actores sociales que forman parte de una cantidad, quizás extensa, de prácticas relevantes.

Entre los criterios para la sistematización de las experiencias de innovación en el campo social (Tabla 10), en el marco del proyecto Experiencias en Innovación Social en América Latina y el Caribe, impulsado por la CEPAL y la Fundación W.K. Kellogg, se definió la innovación como:

"Acción transformadora concreta, generalmente de carácter colectivo, que ofrece una nueva respuesta a un problema determinado. Mediante nuevos procesos, nuevas técnicas y nuevas formas de organizar la acción, se consigue articular una respuesta adecuada a su contexto - llamada inteligencia-con efectos transformadores directos $e$ indirectos más allá de éste. Una innovación es entendida como un cambio reconocido capaz de producir otro cambio. La innovación avanza bajo un imperativo que no cesa: innovar desde la acción para actuar mejor" (Rodríguez \& Alvarado, 2008, 44).

En el mismo contexto de la CEPAL, Rodríguez, Bernal \& Cuervo $(2011,68)$, presentan un interesante aporte con respecto a experiencias innovadoras: "aquellas que han logrado desarrollar nuevas formas de gestión o de operación, que son costo-eficientes y que promueven activamente la participación de los beneficiarios y la comunidad a fin de aportar al fortalecimiento de la democracia en la región".
A partir de la iniciativa CEPAL - W. K. Kellogg, se obtuvieron importantes aprendizajes que se centraron en las opiniones de los representantes de los proyectos (Tabla 11), pero también se extrajeron enseñanzas para el diseño de políticas públicas y para la promoción de la replicabilidad de los proyectos, a partir de la reflexión de los autores del libro: Claves de la innovación social en América Latina y el Caribe, con el apoyo de los miembros del comité de selección que participó en los ciclos, como de los equipos de expertos con los que se realizaron foros virtuales (Tabla 12). En el marco de esta iniciativa y a partir de la pregunta: ¿Cuál es el impacto de las experiencias socialmente innovadoras en el desarrollo económico local de los territorios donde se asientan? Rodríguez, Bernal \& Cuervo (2011) realizaron otro estudio en el que consideran el Desarrollo Económico Local (DEL) en términos de desarrollo social, y siguiendo a Cuervo (2006), lo entienden como: aquel que hace referencia a la capacidad de una sociedad local para formularse metas de interés colectivo y movilizar los recursos necesarios para alcanzar esas metas ${ }^{26}$. En su estudio, consideran 8 experiencias de Argentina, Brasil, Colombia, Ecuador, Haití, México, Paraguay y Perú. A partir de este trabajo presentan sugerencias de política de desarrollo territorial, entrecruzando tres grandes ejes: lo social, lo rural agropecuario y lo local; considerando los criterios estratégicos: integralidad, flexibilidad, descentralización, pluralismo, acción colectiva y sostenibilidad (Tabla 13). Es pertinente anotar que la iniciativa, eventualmente -entre el año 2013 y 2014-, iniciará una nueva fase en América Latina y el Caribe, donde se identificarán experiencias de innovación social que impacten el desarrollo local y surjan de la propia comunidad.

Para finalizar, son oportunas las palabras de Rey \& Tancredi $(2010,47)$, integrantes del Comité de Notables, en el marco del proyecto Experiencias en Innovación Social en América Latina y el Caribe, cuando advierten que:

“(...) como se vio en este ejercicio de cinco años, cuando un proyecto logra resultados

25 Engel $(1997,133)$ se refiere a la práctica agrícola.

26 Al concebir al DEL de esta manera, afirma Cuervo (2006), se asume una postura ética, al considerar que la suerte de una sociedad local depende de los esfuerzos que haga por superar las limitaciones del entorno y aprovechar sus oportunidades, valorizando sus propios recursos. 
Tabla 10. Criterios para definir una innovación ejemplar ${ }^{27}$

\begin{tabular}{|c|c|c|}
\hline \multicolumn{3}{|c|}{ Criterios de selección de innovación social } \\
\hline Social & \multicolumn{2}{|c|}{$\begin{array}{l}\text { Beneficia a un grupo significativo de personas, contribuye a la reducción de la pobreza o a una mejor calidad de vida de los grupos en } \\
\text { riesgo social, reivindica el derecho a un mejor ambiente. }\end{array}$} \\
\hline Genuina & \multicolumn{2}{|c|}{ Emerge de los propios interesados y sus entidades de apoyo, en un proceso verificable. } \\
\hline Original & \multicolumn{2}{|c|}{ No se trata de una experiencia repetida, pero no es necesario que sea un invento. } \\
\hline Vigente & \multicolumn{2}{|l|}{ Es reciente y actual. } \\
\hline Consolidada & \multicolumn{2}{|l|}{ Ha superado la fase de experimentación. } \\
\hline Expansiva & \multicolumn{2}{|c|}{ Podría ser reproducida en otro lugar, a mayor escala 0 ambos. } \\
\hline Transformadora & \multicolumn{2}{|c|}{$\begin{array}{l}\text { Tiene impacto en relación con variables de desarrollo social, como: costos, cobertura, ingreso, empleo, participación, rendimiento, } \\
\text { cultura, calidad de vida, gestión, y creación de nuevas oportunidades. }\end{array}$} \\
\hline \multicolumn{3}{|c|}{ Criterios de postulación, evaluación y premiación } \\
\hline Postulación & Evaluación & Premiación \\
\hline $\begin{array}{l}\text { Carácter innovador de los procesos } \\
\text { Características de la participación }\end{array}$ & $\begin{array}{l}\text { Participación de la comunidad o de los ac- } \\
\text { tores en el proceso innovador }\end{array}$ & Carácter innovador \\
\hline Impacto en calidad de vida & \multirow{3}{*}{ Impacto en calidad de vida } & \multirow{3}{*}{ Significación del impacto } \\
\hline Posibilidad de ampliar cobertura & & \\
\hline Sostenibilidad & & \\
\hline Sustentabilidad & Sostenibilidad & Replicabilidad \\
\hline Replicabilidad & Replicabilidad & \multirow{6}{*}{ Enseñanza } \\
\hline & Pertinencia & \\
\hline & Estabilidad & \\
\hline & Relevancia & \\
\hline & De preferencia: & \\
\hline & Carácter autogestionario & \\
\hline & Organización en redes y alianzas & Asociatividad \\
\hline & \multirow{3}{*}{ Enfoque de género } & Capacidad de entregar un mensaje esperanzador \\
\hline & & $\begin{array}{l}\text { Coherencia con los Objetivos de Desarrollo del Milenio y con los principios de la carta } \\
\text { de las Naciones Unidas }\end{array}$ \\
\hline & & Integralidad \\
\hline \multicolumn{3}{|c|}{ Criterios para la sistematización de experiencias en innovación en el campo social } \\
\hline Asociatividad & \multicolumn{2}{|c|}{$\begin{array}{l}\text { Disposición y capacidad para organizar grupos y movilizar a la comunidad o a un grupo amplio de potenciales beneficiarios que poseen un com- } \\
\text { promiso y una determinada voluntad política, orientada a un objetivo común. Esa voluntad se caracteriza esencialmente por la participación de los } \\
\text { actores en la toma de decisiones y por su capacidad de establecer alianzas sostenibles con diversos actores externos, y sobre todo con instituciones } \\
\text { públicas que suministran apoyo a la innovación y aprenden de ella. }\end{array}$} \\
\hline Integralidad & \multicolumn{2}{|c|}{$\begin{array}{l}\text { Articulación de los conocimientos, las experiencias y los intereses necesarios para una respuesta ambiciosa y equilibrada de los proyectos frente a } \\
\text { situaciones adversas y con alto grado de complejidad. }\end{array}$} \\
\hline Sostenibilidad & \multicolumn{2}{|c|}{$\begin{array}{l}\text { Continuidad en el tiempo gracias a soluciones creativas que se adapten a la restricción de recursos. Esto se logra con fondos propios o de coopera- } \\
\text { ción, y aportes locales y de voluntariado, además de los recursos entregados por los participantes de la comunidad. Este criterio refleja una condición } \\
\text { indispensable de la replicabilidad. }\end{array}$} \\
\hline Novedad & \multicolumn{2}{|c|}{$\begin{array}{l}\text { Acción transformadora concreta, generalmente de carácter colectivo, que ofrece una nueva respuesta a un problema determinado. Mediante nuevos } \\
\text { procesos, nuevas técnicas y nuevas formas de organizar la acción, se consigue articular una respuesta adecuada a su contexto con efectos transforma- } \\
\text { dores directos e indirectos más allá de este. Una innovación es entendida como un cambio reconocido capaz de producir otro cambio. La innovación } \\
\text { avanza bajo un imperativo que no cesa: "innovar desde la acción para actuar mejor". }\end{array}$} \\
\hline Replicabilidad & \multicolumn{2}{|c|}{$\begin{array}{l}\text { Posibilidad de apropiación de las enseñanzas de una experiencia innovadora por otros actores en circunstancias distintas. Se trata de "réplica crea- } \\
\text { tiva", y no simplemente de "copia". }\end{array}$} \\
\hline
\end{tabular}

27 Fuente: Rodríguez \& Alvarado (2008, 47-66). 
Tabla 11. Aprendizajes obtenidos de los proyectos ${ }^{28}$

\begin{tabular}{|c|c|c|}
\hline Categoría & Objetivo principal & Aprendizaje \\
\hline $\begin{array}{l}\text { Proyectos de generación de } \\
\text { ingresos }\end{array}$ & $\begin{array}{l}\text { Promover o aumentar la generación de ingresos de sus be- } \\
\text { neficiarios, quienes generalmente constituyen sus princi- } \\
\text { pales actores. Se ejecutan en zonas rurales o semirurales, } \\
\text { en poblaciones con pocos habitantes, y se han articulado } \\
\text { para dar solución a un problema particular, generalmente } \\
\text { identificado por los propios participantes, de alguna fase } \\
\text { del ciclo de producción y comercialización de un deter- } \\
\text { minado producto. En su mayoría, surgen en situaciones } \\
\text { críticas, en entornos poco favorables e incluso hostiles. }\end{array}$ & $\begin{array}{l}\text { Para lograr el éxito en este tipo de proyectos se requiere que la } \\
\text { respuesta sea integral; es decir, el proyecto debe responder a los } \\
\text { distintos factores implicados y debe contemplar sinergias, como } \\
\text { las que puede haber entre el conocimiento local y el técnico, entre } \\
\text { diversas disciplinas y ciencias, entre factores objetivos y subjetivos, } \\
\text { y entre tecnologías duras, como herramientas, y blandas, como las } \\
\text { organizativas y de gestión grupal. }\end{array}$ \\
\hline $\begin{array}{l}\text { Proyectos de juventud en } \\
\text { riesgo }\end{array}$ & $\begin{array}{l}\text { Atender a jóvenes en situación de alta vulnerabilidad. En } \\
\text { algunos de los proyectos se trabaja con muchachos que } \\
\text { por sus condiciones de vida podrían caer fácilmente en la } \\
\text { delincuencia o la prostitución; en otros, con jóvenes que } \\
\text { enfrentados a la exclusión se han vinculado a pandillas ju- } \\
\text { veniles o actividades delictivas, o que por participar en ac- } \\
\text { tividades de esa naturaleza se encuentran bajo tutela de las } \\
\text { autoridades judiciales. Se originan en situaciones muy crí- } \\
\text { ticas: muchos de los jóvenes enfrentan riesgos de abuso, } \\
\text { violencia, adicción, delincuencia e incluso muerte. Los fra- } \\
\text { casos de muchos proyectos pueden medirse en términos } \\
\text { de vidas humanas perdidas, ya que los jóvenes terminan en } \\
\text { la cárcel, caen en la droga o mueren en la calle a manos de } \\
\text { las mismas pandillas de las que alguna vez formaron parte. } \\
\text { Una vez iniciado el trabajo, la principal dificultad que se } \\
\text { enfrenta es la exclusión de los jóvenes, que opera como } \\
\text { una presión constante; implica que los proyectos deben } \\
\text { superar diversos obstáculos para propiciar la reinserción } \\
\text { de los jóvenes a la vida cotidiana, sea al ámbito educativo, } \\
\text { laboral o familiar. }\end{array}$ & $\begin{array}{l}\text { Es necesaria una estrategia de acompañamiento, orientada a la re- } \\
\text { definición del proyecto de vida de los jóvenes. El acompañamiento } \\
\text { de carácter psicológico debe ser complementado con la atención } \\
\text { integral de las necesidades básicas de esta población, como son } \\
\text { educación, salud, recreación, y empleo. En relación con la recons- } \\
\text { trucción de la subjetividad, es darse cuenta de la necesidad de pro- } \\
\text { piciar un lugar para el joven en su comunidad, que le permita sen- } \\
\text { tirse útil y apreciado. Es necesario lograr un cambio en las expec- } \\
\text { tativas de los jóvenes y apoyarlos en la construcción de un proyecto } \\
\text { de vida en el marco de la ley, la comunidad y la familia, más allá } \\
\text { de la satisfacción inmediata de sus necesidades básicas, modelo } \\
\text { clásico de los esquemas "asistencialistas". Se trata de ayudarlos a } \\
\text { que construyan su propio proyecto de vida hacia una independencia } \\
\text { con responsabilidad. El motor fundamental de cambio tiene que ver } \\
\text { con la recuperación de la esperanza; es la certeza de ese futuro lo } \\
\text { que estos proyectos entregan como mensaje a los jóvenes. }\end{array}$ \\
\hline $\begin{array}{l}\text { Proyectos de afirmación de } \\
\text { derechos }\end{array}$ & $\begin{array}{l}\text { Afirmar los derechos fundamentales de las personas: a la } \\
\text { salud, a la educación, a la no violencia, a la dignidad, a la } \\
\text { expresión. La principal dificultad que han enfrentado casi } \\
\text { todos, especialmente al inicio, se relaciona con el Estado y } \\
\text { las instituciones públicas. En muchos casos, existe todavía } \\
\text { desconocimiento y negligencia con respecto a los peores } \\
\text { problemas de la población, además de falta de sensibili- } \\
\text { dad y experiencia por parte de funcionarios públicos que } \\
\text { se resisten el cambio, en particular en lo que respecta a la } \\
\text { inclusión y participación de las comunidades y las organi- } \\
\text { zaciones civiles en la solución de sus propios problemas. }\end{array}$ & $\begin{array}{l}\text { La exclusión es producto de la falta de oportunidades reforzada con } \\
\text { ausencia de políticas públicas que ofrezcan estímulo y espacios de } \\
\text { participación a las personas. La mejor respuesta es la que consi- } \\
\text { dera la mayor cantidad de factores que limitan la afirmación de un } \\
\text { derecho. Tal respuesta involucra componentes sociológicos, como } \\
\text { la organización; psicosociológicos, como la gestión de grupo; psi- } \\
\text { cológicos, asociados con la situación de una persona vulnerable; } \\
\text { y económicos, como los que corresponden a la administración de } \\
\text { cada proyecto. Es indispensable no excluir a nadie; cuantas más } \\
\text { personas y grupos se sientan miembros de un proyecto o identifi- } \\
\text { cados con él, tanto mejor. Esto implica reconocer al otro, compren- } \\
\text { derlo y considerarlo en la formulación de propuestas. No hay que } \\
\text { olvidar que no se puede construir una identidad, una afirmación, } \\
\text { sino en relación con otros. }\end{array}$ \\
\hline
\end{tabular}

28 Fuente: Rodríguez, Bernal \& Cuervo (2011, 67-71).

* Corresponde a 4 ganadores del ciclo 2004-2005, 16 finalistas del ciclo 2005-2006 y 12 finalistas del ciclo 2006-2007. 
Tabla 12. Enseñanzas útiles en el diseño de políticas públicas y en la promoción de la replicabilidad²9

\section{Algunas enseñanzas generales}

La complejidad de los factores que determinan la exclusión social sólo puede ser enfrentada con una respuesta integral e integradora, esto es, que articule las estrategias necesarias para atacar las diferentes causas del problema respecto del cual se trabaja. Se trata, entonces, de un enfoque multifactorial e interdisciplinario, que debe incluir a tantos actores e intereses como sea posible y contar, especialmente, con la participación activa de la comunidad y los beneficiarios. Estas dos cualidades de la respuesta, integralidad e integración, suponen la complementación entre diferentes tipos de conocimiento, es decir, el diálogo entre personas que saben hacer diferentes cosas, ya que es de esta combinación cooperativa que pueden surgir oportunidades de innovación.

\section{Recomendaciones específicas}

\section{Integralidad}

Desarrollar políticas que promuevan la sinergia entre el conocimiento experto y el local, así como entre el técnico y el tradicional.

Promover la valorización económica del conocimiento local; es decir, considerarlo como un bien y un recurso que puede ser complementado con los conocimientos modernos, pero sin desconocerlo ni subvaluarlo. Dicha valorización del aporte local podría implicar la remuneración u otra forma de reconocimiento, en función de las condiciones particulares.

Identificar la cadena de vulnerabilidades y las respuestas específicas para cada una de ellas.

Adaptar la tecnología social a la cultura, las necesidades, el potencial y el entorno de las poblaciones involucradas.

Promover la tecnología en materia de gestión, contabilidad y costos, formulación de proyectos, evaluación de impacto y sistematización de la experiencia.

Estimular el desarrollo de las capacidades de los diversos actores, dotándolos de instrumentos que aumenten la eficacia de su trabajo y faciliten su participación y la concertación de acuerdos y alianzas.

Promover la transformación cultural de las instituciones, las empresas, las organizaciones y los grupos, así como de sus miembros, a fin de mejorar la receptividad frente a las iniciativas comunitarias y a la innovación.

\section{Integración}

Reconocer que los actores sociales están llamados a jugar un papel clave en la solución de sus problemas, para lo cual es necesaria su participación efectiva, que claramente debe ir más allá de recibir la información.

Propiciar la integración de puntos de vista, conocimientos y prácticas diversos, mediante la formación de equipos con personas de diferentes disciplinas, generaciones y géneros, incluidos no solo agentes externos, sino también miembros de la comunidad.

Favorecer la participación, el empoderamiento y la autonomía de la comunidad, por medio de la definición de sus necesidades y prioridades, así como de las opciones para hacerles frente y la forma en que estas se ejecutan y evalúan.

Facilitar el desarrollo de la gestión grupal, en relación con las estrategias que fomenten el surgimiento de respuestas innovadoras.

Promover el desarrollo de liderazgos orientados a la cooperación y la productividad de los grupos, capaces de fomentar su propia renovación y, por lo tanto, de encontrar gratificación al estimular la participación ciudadana.

Propiciar la articulación de los programas del sector público, de los gobiernos locales, de la iniciativa privada y de la comunitaria, sobre la base del reconocimiento, la promoción y el apoyo de las experiencias innovadoras.

Procurar la articulación de los distintos niveles del gobierno y su relación con la sociedad civil -organizaciones no gubernamentales y de la propia comunidad-, a fin de que las propuestas localizadas encuentren eco a escala regional, nacional e incluso internacional.

29 Fuente: Rodríguez \& Alvarado (2008, 47-66). 
Tabla 13. Sugerencias de política de desarrollo territorial: lo social, lo rural agropecuario y lo local ${ }^{30}$

\section{Integralidad}

En las experiencias analizadas, por rutas y con intensidades diferentes, un rasgo común es la intervención simultánea en frentes complementarios, tales como: la asistencia técnica y productiva, el fortalecimiento organizacional, la capacitación social y tecnológica, el apoyo a la comercialización y la generación de formas de ahorro y crédito. Sugerir la necesidad de políticas integrales para la promoción del desarrollo territorial no es, desde la teoría, ninguna novedad. No obstante, en la práctica, la aplicación de esta recomendación no es lo frecuente que se quisiera y es allí donde radica la riqueza de estos casos. Este criterio de integralidad es especialmente pertinente para los modelos de asistencia técnica y extensionismo rural. Se sugiere entonces que éstos no se restrinjan al fortalecimiento y fomento productivo y aún menos si se le enfoca exclusivamente a la elaboración de materias primas. Es indispensable que incluyan capacitación y asesoramiento para consolidar la comercialización, generar estrategias, canales, y apertura de mercados y, mejor aún, ampliar los procesos de transformación de los bienes producidos o complejización de los servicios entregados.

\section{Flexibilidad}

Cada experiencia se desenvuelve en un contexto histórico, social e institucional, tan específico que el éxito de la política pública parece estar en proporción inversa a su rigidez. Se requiere entonces de políticas y programas públicos con suficiente maleabilidad y capacidad de adaptación a las circunstancias propias de tiempo y lugar.

\section{Descentralización}

La flexibilidad institucional, necesaria para adaptarse a las circunstancias específicas de cada lugar, es más fácil de construir si hay una mayor cercanía entre los tomadores de decisiones públicas y los beneficiarios de sus políticas. Esto se puede alcanzar a través de la descentralización y puede, además, ocurrir a diferentes escalas, es decir, que no necesariamente debe reposar en la más local (municipal o comunal). Es aconsejable promover el traspaso de funciones y recursos del nivel central al regional-local, es decir, la descentralización - acompañado de los recursos necesarios para que no quede sólo en la retórica legal.

\section{Pluralismo}

Otro de los ingredientes explicativos del éxito, de varias de las experiencias estudiadas, recae en su apertura y capacidad para recuperar y adaptar conocimientos técnicos y ambientales tradicionales. Para conseguir esta apertura, es necesario desarrollar actitudes y habilidades institucionales, para conocer y reconocer estos conocimientos e incorporarlos a las propuestas formales previamente existentes. En todos los casos aquí analizados, se identificó como uno de los factores de éxito, la capacidad de articular los dos tipos de conocimientos, tomando siempre lo mejor de ellos.

\section{Acción colectiva}

Las habilidades sociales, de coordinación y de trabajo en equipo, son cruciales en la explicación del éxito en las experiencias estudiadas. La asociatividad entre productores es una de las claves del éxito, siendo así de gran importancia que los programas de extensión y asistencia técnica a productores, involucren dentro de sus estrategias la promoción de la asociatividad, en las fases de compra de insumos y utilización de maquinaria y herramientas, y luego en la transformación y comercialización de los productos. Estas habilidades de acción colectiva no son un reto exclusivamente para la sociedad civil, sino que también comprometen las formas de actuar de las instituciones públicas.

\section{Sostenibilidad}

Por lo general, las experiencias toman de una a dos décadas antes de consolidarse. Esto no significa, sin embargo, que no hayan producido resultados positivos a corto plazo. No obstante, las posibilidades de incidir significativamente, en la promoción de procesos de desarrollo propiamente dichos, se da a escalas de tiempo un poco más largas. Por lo tanto, no sorprende que las experiencias con mayor trayectoria, sean las que hayan logrado incorporar objetivos sociales y ambientales, junto con los económicos, de manera que sus resultados han logrado ser un aporte al bienestar de la comunidad donde se insertan. En la mayoría de los casos ha habido un reconocimiento y visualización del aporte de las mujeres dentro de las organizaciones. Varias experiencias han asumido la protección del medio ambiente a la par con las mejoras en la producción, compromiso que ha sido fundamental para insertarse en mercados verdes. Para los diseñadores y ejecutores de la política pública social, de desarrollo económico local y rural, es muy importante tener en cuenta la necesidad de darle continuidad a sus acciones, durante los lapsos de tiempo que ellas requieren para producir los resultados esperados.

30 Fuente: Rodríguez, Bernal \& Cuervo (2011, 67-71). 
significativos y consigue captar la atención del Estado, hasta el punto que lo reconoce, adopta y lo reproduce en otras regiones, puede pensarse que éste puede masificarse y ser sostenible. Este es el tránsito de un proyecto aislado hasta un programa que se convierte en política pública. Por ello, es imperativo que se produzca un diálogo entre quienes se mueven en el ámbito de este tipo de proyectos y el Estado, proceso que puede ser muy productivo".

\subsection{Análisis de conjunto}

No obstante la aparente vaguedad y ambigüedad implicada en los diversos discursos originados en audiencias de diferentes disciplinas que se pueden apreciar y leer en los párrafos que preceden sobre innovación social, se puede observar que el hilo conductor de tales discursos, indica que ella es comprendida como proceso social y como fenómeno emergente en el contexto de prácticas ciudadanas que enfrentan problemas sociales; que privilegia intereses colectivos sobre individuales y que fortalece las capacidades de unos y de otros. Así entendida (como proceso social), implica aprendizaje e interacción comunicativa, aspectos propios de una práctica continua y dinámica, que se funda en el individuo, pero que se forja en lo colectivo (López-Isaza, 2013a).

Concebir la innovación y el conocimiento como proceso social, es promisorio y generativo, pues reconoce, respeta, pondera y valora las emociones ${ }^{31}$, los diferentes saberes y conocimientos de las personas que participan en su construcción colectiva, y a la vez permite comprender que aquello que aparece como producto es sólo un eslabón de un bucle, espiralado y sin fin, que contiene realizaciones y emergencias de posibilidades.

Abordar la innovación social implica reconocer su complejidad, ya que compromete tanto su historia intelectual como a diferentes actores públicos, privados, civiles y académicos, todos ellos con la presun- ción de que pueden y deben hacer algo con respecto, no tanto al mismo concepto, sino a su realización, como panacea a la solución de los problemas que en la actualidad experimenta la humanidad, buscando por ello su incorporación en la agenda de problemas socialmente vigentes.

La innovación social se ve afectada por los significados sociales que los interesados en ella le otorgan. Entonces la educación (entendida como proceso comunicativo), es clave en la configuración de tales significados, los cuales coexisten y obran recíprocamente con las respuestas personales y la experiencia existencial de los individuos (Pacey, 1999; López-Isaza, 2006), afectando la toma de decisiones de quienes asumen su fomento. Innovar es un objetivo a realizar, pero también forma parte de la condición humana, de su capacidad creativa y de su motivación, para buscar nuevas oportunidades y emprender nuevas iniciativas en búsqueda de un presente mejor.

La elevada abstracción y riqueza que alcanza el significado de innovación social, configura un reto para abordarlo a través de bases teóricas y metodológicas comparables internacionalmente con indicadores empíricos construidos, sin que la relación concepto/indicador/operativización, establezca un vínculo unívoco, es decir, sin que su fecundo y promisorio concepto se agote y sea leído completamente, pues al momento de gestionar la innovación (en general), es necesario considerar que no es ni excepcional, ni espontánea; por el contrario, su carácter es deliberado e intencional, demanda entornos que estimulen procesos de destrucción creativa embebidos en la sociedad/comunicación, con el propósito social de lograr una mejor calidad de vida.

\section{Educación, nutriente de la innovación social}

La innovación social implica la relación participación ciudadana/usuario, como también la co-creación, ambas favorecidas por una educación concebida

31 Según Damasio (2010b, 46-49) las emociones propiamente dichas son: repugnancia, miedo, felicidad, tristeza, simpatía y vergüenza. Estas emociones propiamente dichas se clasifican en: emociones de fondo, como energía o entusiasmo, malestar o excitación, nerviosismo o tranquilidad; emociones primarias o básicas, como miedo, ira, asco, sorpreza, tristeza y felicidad; y emociones sociales, como simpatía, turbación, vergüenza, culpabilidad, orgullo, celos, envidia, gratitud, admiración, indignación y desdén. 
como bien en sí, que permite ampliar las capacidades del individuo y su participación en la vida social, con inclusión activa de la otredad; que valora, enriquece y coordina la inteligencia distribuida en la ciudadanía -inter legere- como punto de unión de ideas, de saberes y de personas que son usuarias/ proveedoras, que construyen sociedad, y favorecen circuitos innovadores -interacciones que posibilitan encuentros conversacionales entre quienes tienen un problema y los que tiene la solución-y fusiones creativas -resultado de la colisión de diferentes mundo mentales, que se unen en un acto de co-creación, como uno sólo alrededor de y en una innovación(López-Isaza, 2013b). Teniendo en cuenta lo anterior, antes de profundizar en el tema de la educación, se expondrán sucintamente algunos aportes de diferentes autores sobre ciudadanía:

- La ciudadanía, como concepto complejo, multidimensional y polisémico se construye como resultado de procesos históricos, culturales, sociales y económicos de cada territorio. Se puede rastrear en la época actual, desde Marshall (1950) concepción tripartita de derechos (civil, político y social); Young (1989) "ciudadanía diferenciada"; Touraine (1997, 2001) pertenencia a una sociedad política organizada y controlada por sí misma, reducción del individuo al ciudadano y a la vez afirmación de que el poder político no tiene otro fundamento legítimo que la soberanía popular; Margalit (1997) adición de ciudadanía simbólica a los elementos marshalianos; Cortina (1998, 2004) ganancia de un proceso que empieza con la educación formal e informal y la idea de ciudadanos cosmopolitas; Ocampo (2000) reclamo, reparto y protagonismo en los flujos de información, en la circulación de conocimientos $y$ en el diálogo mediático en las sociedades de información de hoy; Heater (2007) relación de un individuo básicamente con la idea de estado; Pasquino (2001) política de inclusión máxima en la idea de ciudadanía mundial; Nussbaum (2005, 2010) cimentada en las artes y las humanidades; Ayllón (2011) construcción de una ética basada en la reiterada práctica política de la igualdad legal, social y humana, pertenencia activa $e$ integración social que tiene su primera escuela en la familia y la red familiar más amplia.
- Significa según Ocampo (2000) una comunidad de personas que no se restringen sólo a sus actividades privadas, sino que además concurren en el espacio y el debate públicos para participar en proyectos y en decisiones compartidas. La promoción de la ciudadanía significa, en primer término, el desarrollo de la ciudadanía civil, entendida básicamente como el respeto a la autonomía de las personas. En segundo lugar, significa el desarrollo de la ciudadanía política, es decir, la extensión de la gama de agentes de la sociedad que participan en los procesos deliberantes y decisorios. En tercer lugar, la promoción de la vigencia de los derechos económicos, sociales y culturales, dentro de los límites de las posibilidades de cada sociedad. En las sociedades de información de hoy, es también, la capacidad de disponer de los conocimientos y bienes necesarios para participar como actores en los flujos de información, en la circulación de conocimientos y en el diálogo mediático, y para adaptarse a nuevos procesos de gestión y organización que la propia sociedad, a través de sus organizaciones, va forjando. La ciudadanía es una condición de libertad privada y de derechos políticos básicos y también una condición que atañe a la calidad de vida de todos aquellos que forman parte de la sociedad (López-Isaza, 2013b, 7-8).

Tomando en consideración los anteriores aportes sobre ciudadanía, podemos comprender la necesidad de distinguir que: la educación se da al ser humano desde la familia, la escuela y la sociedad; lo forma en apertura al mundo, a los otros y con los otros, en comunicación, en imaginación y en lenguaje. Pero en el contexto de este trabajo, el autor refiere a una educación humanizada, pensada en y para el mundo de la vida. Concibe que la educación en sí y para sí misma constituye savia que abre, penetra y altera mentes, que riega y nutre gérmenes que enraízan y brotan como simientes de innovación social.

A partir del acercamiento anteriormente presentado a la innovación social, se relacionan algunas miradas teóricas que contribuyen al enriquecimiento del concepto. Así, se rescata de Cortina $(1998,2004)$ el hecho de entender el papel vital de la educación en la 
innovación social, sobre la meta de la universidad; de Gutiérrez (2007) con respecto de asumir la cuestión educativa desde una actitud filosófica; de Nussbaum (2005, 2010) con el cultivo de la humanidad y sin fines de lucro; de Hoyos (2007), a partir del mundo de la vida como base de experiencia personal y colectiva; y de Dewey (2007), con respecto a transformar el lenguaje en una herramienta intelectual:

Dice Cortina (2008, 301), en homenaje a Guillermo Hoyos, que es necesario integrar las dos metas de la universidad de los modelos medieval y liberal, en una tercera meta:

"La educación de ciudadanos «arraigados", con su comunidad local y con la global, conscientes de ser ciudadanos del mundo y de su comunidad concreta, sabedores de que «ciudadanía obliga» a trabajar por el mundo al que se pertenece como ciudadano".

De cumplirse la meta propuesta por Cortina (2008) claramente se aprecia el aporte de la educación a la innovación social, pues el ciudadano, al ser consciente de su pertenencia a una comunidad y de sus compromisos como tal, se ve impelido a imaginar, pensar, inventar, proponer, compartir e implementar ideas de posibles soluciones a las problemáticas que en la cotidianidad de su realidad encuentra.

A su vez, Gutiérrez (2007, 137) argumenta sobre la conveniencia de asumir la cuestión educativa desde una actitud filosófica, entendida como:

"Una acción fundamentalmente constitutiva de un ser que se hace y se rehace en su lucha por devenir en la cultura y en la sociedad, en contra de apariencias de autonomía y singularidad avasalladoras de donde sólo es posible salir si se tiene la disposición de subvertir la obviedad. Pues la simple adaptación no ha de ser confundida con el educarse, menos con el formarse, pues para avanzar en tal perspectiva, como en toda utopía, la prefiguración de lo deseable apenas sirve para estar en movimiento: paradójicamente, para la propia negación".
Gutiérrez (2007, 169) asume la actitud filosófica desde el ser total, desde el ser que piensa sintiendo y siente pensando; desde el ser que piensa impulsado por tensiones como el deseo y el temor, desde el ser que al mismo tiempo se siente movido por el saber y por la duda.

Aceptar la invitación del profesor Gutiérrez para asumir la educación con actitud filosófica, implica comprendernos como seres abiertos, indeterminados $y$ no prefijados en el mundo; con la responsabilidad que nos representa el privilegio que tenemos de imaginar, pensar, inventar, innovar, aprender, lenguajear; y desde el reconocimiento de esta responsabilidad, interrogar el mundo a partir de lo que somos, de nuestras expectativas, de nuestras necesidades; extrañándonos, significándonos, resignificándonos y familiarizándonos, con nosotros mismos y con nuestra realidad, con emoción, razón y sentimiento. Es la apuesta que interpreto que Gutiérrez (2007) nos propone y que al aceptarla, hace de la educación simiente de la innovación humana y social.

Nussbaum $(2005,28)$ a partir de su comprensión del quehacer de las escuelas superiores y universidades norteamericanas, identifica "tres habilidades para cultivar la humanidad" en una educación inspirada en las humanidades. Con relación a este tipo de educación, Nussbaum $(2010,82)$ expresa que:

"La educación humanística fortalece las capacidades de la imaginación y la independencia de criterio, fundamentales para una cultura innovadora, llama la atención sobre el hecho de que parece ser que uno de los rasgos distintivos de Estados Unidos reside en el predominio de la educación humanística (aunque en peligro) y de la educación científica general, basada en la investigación, más que en la ciencia aplicada".

Las habilidades de las que habla Nussbaum (2005, $28,29,30,33$ ) se relacionan con la destreza y disposición para cuestionar toda forma de dogmatismo $e$ imposición de creencias y conocimientos, aceptando sólo "lo que sobrevive a lo que la razón exige en cuanto a coherencia y justificación"; para concebirnos como seres interculturales, es decir para "estar 
conscientes de las muchas posibilidades de comunicación con otros seres humanos, y de las responsabilidades que se pueden tener con ellos"; y para tener empatía, esto significa que el ciudadano, además de aprender una serie de hechos y de manejar técnicas de razonamiento, debe aprender a ser un ser humano capaz de amar e imaginar "cómo sería estar en lugar de otra persona", para así y desde la aproximación a la interpretación del mundo desde el punto de vista de esa otra persona, emitir juicios responsables, ponderando "el medio social que configura las aspiraciones y emociones" de tal persona.

Los aportes de Nussbaum (2005) ayudan a comprender que el ámbito de entendimiento de los ciudadanos, como seres humanos que somos, nace precisamente de nuestra propia humanidad, en la que como co-creadores del acto mismo y del deseo de actuar en un mundo social, somos individuos embebidos en el colectivo y éste en nosotros mismos. Y así, como usufructuarios de una educación humanista, nos podemos concebir y valorar como seres plurales y totales, revelados en un individuo, conjurando clausuras de burbujas lógicas, que implicadas por modelos mentales rígidos, vulneran sensibilidades a diferencias que son connaturales a la existencia humana, y que como tales favorecen posibilidades de innovación, al ser ésta precisamente, ganancia y promotora de diferencias conversadas.

Hoyos $(2007,149)$ partiendo del mundo de la vida como base de experiencia personal y colectiva, incluyendo todas las personas y culturas que forman una sociedad, expresa que la educación es:

"El proceso en el que se nos abren diversos mundos, formas de organización y sentidos de la vida. Afirma que aquí se encuentra el principio fundamental de toda moral y de las competencias ciudadanas al leer en el rostro del otro las luchas por el reconocimiento, cada uno desde sus visiones omnicomprensivas de la vida, la historia, la religión y los valores; que dentro de la concepción discursiva de la educación, de las formaciones sociales con ayuda de la teoría del actuar comunicacional, la comunicación en la sociedad no busca sólo la comprensión, sino que se afana por el entendimiento mutuo en torno a intereses determinados; que la educación, dentro de un paradigma discursivo, anima la complejidad de la sociedad civil y fomenta el pluralismo razonable".

Precisamente una educación en clave de mundo de la vida y dentro de una concepción discursiva, promueve el entendimiento sobre que vivir y conversar son actos conectados, que conversar enlaza mentes y mundos; tal educación facilita la conversación de saberes, desde diferentes mundos, ponderando los conocimientos académicos, pero también los expertos y los prácticos, los de las ciencias naturales, los de la discusión, los tradicionales o ancestrales, los vernáculos, los religiosos, y todos aquellos conocimientos que son expresión del acontecer humano; propiciando conversaciones estructuradas para lenguajear, respetando y valorando la pluralidad de paisajes taxonómicos y léxicales, de quienes son expresión de esos diversos saberes, pues una educación así, entiende que tal complejidad favorece la innovación como proceso social a partir del actuar comunicacional.

Un ejemplo de como la educación permite preservar un tipo de conocimientos, que bajo el deslumbramiento generado por los científicos y tecnológicos, son muchas veces ignorados - me refiero a los conocimientos tradicionales-, consiste en que justamente, a través de la educación, es posible establecerlos como procesos vivientes en la práctica social ciudadana, revitalizándolos permanentemente para asegurar su actualidad, continuidad y valoración por parte de la sociedad, y posibilitar de esta forma, la generación de nuevas técnicas, incluso de nuevas combinaciones o configuración de nuevos materiales, que permitan la cualificación de prácticas ancestrales, manteniendo y vigorizando las tradiciones. De esta manera, nutriendo la tradición, la educación posibilita la innovación.

Dewey $(2007,239)$ distinguiendo entre el uso práctico y social y el uso intelectual del lenguaje, afirma que la "educación tiene que transformar el lenguaje en una herramienta intelectual", se trata de "orientar el lenguaje oral y escrito de los alumnos, que se utili- 
za primordialmente con fines prácticos y sociales, de tal modo que poco a poco se convierta en una herramienta consciente para vehicular el conocimiento y apoyar al pensamiento".

La pertinencia de este aporte, al promover el lenguaje como vehículo de conocimiento y apoyo al pensamiento, radica en que a través de las estructuras léxicales y taxonómicas que se encuentran en nuestra mente y que comprenden nuestro lenguaje, vivimos y conversamos; y que como actos conectados que son, pues a partir de él comprendemos, construimos y nos acercamos a mundos y realidades diversas, hacemos uso de la imaginación y nos relacionamos socialmente.

El pensamiento, nutrido por el lenguaje, se constituye especulativo, y como tal, vive una transición desde la contemplación y observación pasiva de las manifestaciones de la naturaleza, hacia una mayor interacción entre los seres humanos y los fenómenos que los rodean. Estos cambios, unidos a los que caracterizan la forma de generar conocimientos, exhiben una gradual y dispar progresión hacia el uso de la razón, como medio principal para estructurar nuevas apreciaciones sobre el mundo físico, social, intelectual y espiritual. El lenguaje, la comunicación y la percepción, a través de sentidos y mente, actúan entre sí recíproca y sutilmente.

Así, una visión de mundo y un lenguaje, pueden reforzarse el uno al otro de manera que cada persona que apalabra tal lenguaje, está inconscientemente dispuesta a ver el mundo desde el lente que le permite ese lenguaje: he aquí que el lenguaje usado refleja una visión de mundo. De tal suerte que si queremos otro diferente, apremia entonces un cambio de léxicos; un nuevo lenguaje aflora y se potencia la eclosión de una innovación.

\section{Una tesis/conclusión}

A partir de lo expresado en los párrafos anteriores, una tesis/conclusión que se obtiene es:

"La educación/comunicación infunde savia que abre, penetra y altera mentes; con emoción, razón y sentimiento, siembra, riega y nutre gérmenes que enraízan y brotan como simientes que otorgan sentido a la innovación, como constructo y esperanza social; con la participación/conversación de ciudadanos plurales y totales, inflama sinapsis que favorecen fusiones creativas que configuran innovación social" (LópezIsaza, 2013a).

La innovación, además de ser un fenómeno económico, es también un fenómeno social complejo, se identifica que es conocimiento en acción distribuida, interactiva y colectiva, que eclosiona en la metainvención y en la metainnovación ${ }^{32}$, ambas primeramente modeladas por la lengua y mediadas por espacios de aprendizaje, que es el núcleo del desarrollo económico, el bienestar social y la protección del ambiente y la vida (López-Isaza, 2013b).

Considerar la innovación como:

“(...) potencial realizado, revelante de transformaciones silenciosas y, a la vez, como emergencia de posibilidades a partir de ambientes integradores y acumulativos de aprendizajes y emociones, que implican encuentros de voluntades razonables ${ }^{33}$ $y$ socialización en un contexto dado, en donde tales encuentros implican: estructuras societarias que los posibilitan, pueden llevar a producir nuevos desciframientos,

32 La metainnovación o innovación conceptual (Gehlen, 1986), se genera en y a partir de un sistema conceptual en el que habita quien la concibe. En dicho sistema emerge lo que Murray (2003) denomina: metainvención, una herramienta cognitiva e intangible que faculta a los seres humanos para realizar otras invenciones y descubrimientos, produciendo, en consecuencia, nuevos logros y transformaciones cognitivas.

33 Según Rancière (2003) la voluntad razonable es el arte de vencerse uno mismo; es la que dice y hace experimentar a los otros aquello en lo que se es semejante a ellos; a través de ella se guía libremente la inteligencia puesta al servicio de los individuos. 
involucran procesos de comunicación intensiva, configuran capacidades específicas de absorción y generación de conocimiento para un territorio dado, y favorecen desplazamientos detonantes de posibilidades" (López-Isaza, 2013b, 15).

Permite visualizar el carácter de novedad a partir de "potenciales realizados" y de la "emergencia de posibilidades"; que es axiológica en la medida en que tal novedad implica una teoría de los valores; que le da un origen a la innovación al colocar su génesis a partir de ambientes integradores y acumulativos de aprendizajes y emociones, en donde las personas aprenden a través del trabajo conjunto y trabajan en conjunto a través del aprendizaje, comprometiendo en ello la concurrencia de voluntades razonables mediante procesos de socialización, pues la innovación es un acontecimiento colectivo de principio a fin que involucra competencia social.

Innovación y ciudadanía se funden a través de la educación como comunicación, y esta última como competencia ciudadana por excelencia. Implica movilización individual y colectiva, en la que a partir de la diversidad e interacción comunicativa se genera sinergia cognitiva para la acción, en un bucle en el que la innovación fortalece a la ciudadanía y esta su génesis (López-Isaza, 2013b, 15).

Finalmente, como se evidencia en este documento, es necesaria una mayor observación, distinción y construcción de las características particulares de la innovación social y de su concepto, como también la incorporación del mismo en una teoría integral de la innovación o viceversa, o considerar la posibilidad de en vez de hablar del concepto, hablar de las dinámicas, los enfoques o características de la innovación social.

\section{Referencias}

Ayestarán, I. (2011). Epistemología de la innovación social y de la destrucción creativa. En: Utopía y praxis latinoamericana, 16 (54): 67-91.

Ayllón, M. (2011). La territorialidad de la familia en la construcción de ciudadanía democrática. En: Ayllón, M., Nuño, M. \& Brinckman, W. (Coords.). Familia, identidad y territorio: 17-47. España: Eumed.net.
BEPA - Bureau of European Policy Advisers (2011). Empowering people, driving change: Social innovation in the European Union. Luxembourg: Publications Office of the European Union.

Bercovitz, A. (Coord.) (1994). Nociones sobre patentes de invención para investigadores universitarios. Paris: Ediciones UNESCO/ CRE - Columbus.

Buckland, H. \& Murillo, D. (2013). Antena de la innovación social. Vías hacia el cambio sistémico. Ejemplos y variables para la innovación social. Barcelona: Instituto de Innovación Social, ESADE, Universidad Ramón Llull.

Castells, M. (2009). Comunicación y poder. Madrid: Alianza Editorial, S. A.

Cajaiba-Santana, G. (2013). Social innovation: moving the field forward. A conceptual framework. Technological Forecasting \& Social Change. Article in press. Disponible en: http://dx.doi. org/10.1016/j.techfore.2013.05.008

Ceberio, I. (2009). Innovación y creatividad en las personas. Apuntes psicológicos. En: Maidagán, M. et al. (eds.) Filosofía de la innovación: el papel de la creatividad en un mundo global. Madrid: Plaza y Valdes Editores: 169-177.

Cortina, A. (1998). Ciudadanos del mundo. Madrid: Alianza Editorial.

Cortina, A. (2004). Educar para una ciudadanía cosmopolita. Disponible en: http://elpais.com/diario/2004/02/11/opinion/1076454006_850215.html

Cortina, A. (2008). La ética de la actividad universitaria. En: Rocha, A. (ed.) La responsabilidad del pensar: homenaje a Guillermo Hoyos Vásquez. Barranquilla: Ediciones Uninorte: 280 - 310.

Crises. (2013). Depliant crises 2011. Disponible en: http://www. crises.uqam.ca/presentation-es

Cuervo, L. (2006). Aprender, comunicar, comprender: un balance crítico de la teoría del desarrollo económico local. Santiago de Chile. Mimeo.

Damasio, A. (2010a). Y el cerebro creó al hombre. ¿Cómo pudo el cerebro generar emociones, sentimientos, ideas y el yo? Barcelona: Ediciones Destino, S. A.

Damasio, A. (2010b). En busca de Spinoza neurobiología de la emoción y los sentimientos. Barcelona: Crítica, S. L.

Dewey, J. (2007). Cómo pensamos. La relación entre pensamiento reflexivo y proceso educativo. España: Paidós.

Engel, P. (1997). The social organization of innovation. A focus on stakeholder interaction. Amsterdan: KIT Press Royal Tropical Institute-CTA-STOAS.

European Commission. (2013). Guide to social innovation. Disponible en: http://ec.europa.eu/regional policy/sources/docgener/ presenta/social_innovation/social_innovation_2013.pdf

Franz, H., Hochgerner, J. \& Howaldt, J. (eds.) (2012). Challenge Social Innovation. Potentials for business, social entrepreneurship, welfare and civil society. Berlin: Springer: 1-16 y 379-384.

Gehlen, A. (1986). Urmensch und spätkultur. En: Maidagán, M., Ceberio, I., Garagalza, L. \& Arrizabalaga, G. (eds.). Filosofía de la innovación: el papel de la creatividad en un mundo global. Madrid: Plaza y Valdés Editores: 33-44.

Gibbons, M., Limoges, C., Nowotny, H., Schwartzman, S., Scott, P. \& Trow, M. (1994). The new production of knowledge: science and research in contemporary societies. Barcelona: Pomares-Corredor.

Gibbons, M. (1998). Higher education relevance in the 21st century. Alexandria (Virginia): The World Bank Human Development Week '98. 


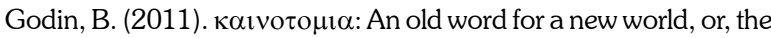
de-contestation of a political and contested concept. Working Paper $N^{\circ}$ 9. Disponible en: http://www.csiic.ca/innovation.html

Godin, B. (2012a). Social innovation: utopias of innovation from c.1830 to the present. Project on the intellectual history of innovation. Working Paper $N^{\circ} 11$. Disponible en http://www. csiic.ca/innovation.html

Godin, B. (2012b). Innovation and conceptual innovation in ancient greece. Project on the intellectual history of innovation. Working Paper $\mathrm{N}^{\circ}$ 12. Disponible en: http://www.csiic.ca/innovation.html

Godin, B. (2013). Science, technology and innovation. The idea of innovation. Disponible en: http://www.csiic.ca/innovation.html

Goodman, J. \& Murillo, D. (2011). Antena de la innovación social. Las diez innovaciones sociales más destacadas e inspiradoras. Barcelona: Instituto de Innovación Social, ESADE, Universidad Ramón Llull.

Granés, C. (2011). El puño invisible. Arte, revolución y un siglo de cambios culturales. México D. F.: Santillana Ediciones Generales, S. A. Taurus.

Gutiérrez, E. (2007). La actitud filosófica. En: Hoyos, G., Serna, J. \& Gutiérrez, E. Borradores para una filosofía de la educación. Bogotá D. C.: Siglo del Hombre Editores - Rudecolombia: $129-179$.

Heater, D. (2007). Ciudadanía una breve historia. Madrid: Alianza Editorial.

Hochgerner, J. Howaldt, J. \& Schindler-Daniels, A. (2011). CSI Challenge social innovation. Innovating innovation by research - 100 years after Schumpeter. ICICI 2011 International conference on indicators and Concepts of innovation. Disponible en: http://www.socialinnovation2011.eu/

Hochgerner, J., Franz, H., Howaldt, J. \& Schindler-Daniels, A (2011). Vienna declaration: the most relevant topics in social innovation research. Challenge social innovation. Innovating innovation by research - 100 years after Schumpeter. 19-21 September 2011. Disponible en: http://www.socialinnovation2011.eu/

Hoyos, G. (2007). La comunicación: la competencia ciudadana. En: Hoyos, G. \& Ruiz, A. (comp.) Ciudadanías en formación. Bogotá: Cooperativa Editorial Magisterio: 135 - 172.

Hubert, A. (2012). Foreword I. En: Franz, H., Hochgerner, J. \& Howaldt, J. (eds.) Challenge social innovation. Potentials for business, social entrepreneurship, welfare and civil society. Berlin: Springer: v-x.

Innobasque (2013). RESINDEX, un modelo propio para medir la innovación social. Disponible en: http://www.innobasque.com/ home.aspx?tabid $=20 \&$ idNoticia $=1078 \&$ mostrar $=P$

López-Isaza, G. (2006). Perspectivas para el análisis de la innovación. Un recorrido por la teoría. En: Cuadernos de Administración, 19(31): 243-273.

López-Isaza, G. (2013a). Emprenderismo/educación, innovación/ educación, empleo/educación: lenguajes que atrapan sentidos. Trabajo no publicado. Pereira: Doctorado en Ciencias de la Educación. Área de Pensamiento Educativo y Comunicación. Rudecolombia. Universidad Tecnológica de Pereira.

López-Isaza, G. (2013b). Aportes teóricos para la gestión y política de innovación en función de la ciudadanía. En: Innovar, 23(47): 5-17.

Luhmann, N. \& Schorr, K. (1993). El sistema educativo (problemas de reflexión). México: Universidad de Guadalajara, Universidad Iberoamericana, Instituto Tecnológico y de Estudios Superiores de Occidente.
Maidagán, M., Ceberio, I., Garagalza, L. \& Arrizabalaga, G. (eds.) (2009). Filosofía de la innovación: el papel de la creatividad en un mundo global. Madrid: Plaza y Valdes Editores.

Margalit, A. (1997). La sociedad decente. Barcelona: Ediciones Paidós Ibérica, S.A.

Marshall, T. (1950). Citizenship and social class, and other essays. Cambridge, UK: University Press.

Murray, C. (2003). Human accomplishment: the pursuit of excellence in the arts and sciences, 800 B.C. to 1950.NY: Perennial, Harper Collins Publishers.

Nussbaum, M. (2005). El cultivo de la humanidad. Una defensa clásica de la reforma en la educación liberal. Barcelona: Ediciones Paidós.

Nussbaum, M. (2010). Sin fines de lucro. Por qué la democracia necesita de las humanidades. Madrid: Katz Editores.

Ocampo, J. (coord.) (2000). Equidad, desarrollo y ciudadanía. Chile: Naciones Unidas-CEPAL.

Pacey, A. (1999). Meaning in technology. Cambridge: The MIT Press.

Pasquino, G. (2001). Ciudadanía mundial. En: Psicología política, 23: 59-75.

Rancière, J. (2003). El maestro ignorante: cinco lecciones sobre la emancipación intelectual. Estrach, N. (trad.). Barcelona: Editorial Laertes, S.A.

Reinert, H. \& Reinert, E. (2006). Creative, destruction in economics: Nietzsche, Sombart, Schumpeter. En: The European Heritage in Economics and the Social Sciences, Springer Link, 3: 55-85.

Rey, N. \& Tancredi, F. (2010). De la innovación social a la política pública. Historias de éxito en América Latina y el Caribe. Santiago de Chile: Naciones Unidas - Comisión Económica para América Latina y el Caribe -CEPAL.

Rüede, D. \& Lurtz, K. (2012). Mapping the various meanings of social innovation: Towards a differentiated understanding of an emerging concept. Research Paper 12-03. Oestrich-Winkel: EBS Business School Universität für Wirtschaft und Recht, Center for Social Innovation and Social Entrepreneurship. Disponible en: http://www.ebs.edu/?id=4176\&L=1

Rodríguez, L., Bernal, M. \& Cuervo, L. (2011). Innovación social y desarrollo económico local. Santiago: Naciones Unidas - Comisión Económica para América Latina y el Caribe (CEPAL).

Rodríguez, A. \& Alvarado, H. (2008). Claves de la innovación en América Latina y el Caribe. Santiago de Chile: Naciones Unidas - CEPAL.

Sábato, J. \& Botana, N. (1968). La Ciencia y la Tecnología en el Desarrollo de América Latina. En: Sábato, J. (comp.) (1975). El pensamiento latinoamericano en la problemática cienciatecnología-desarrollo-dependencia. Buenos Aires. Editorial Paidós: 143 - 158.

Sagasti, F. (2011). Ciencia, tecnología, innovación. Políticas para América Latina. Lima: Fondo de Cultura Económica.

Santos, B. (2003). Crítica de la razón indolente: contra el desperdicio de la experiencia. Para un nuevo sentido común: la ciencia, el derecho y la política en la transición paradigmática. Vol. 1. Bilbao: Desclée de Brouwer, S.A.

Santos, B. (2009). Una epistemología del Sur: la reinvención del conocimiento y la emancipación social. México: Siglo XXI y CLACSO.

Schumpeter, J. (1934). Theorie der wirtschaftlichen entwicklung. Eine untersuchung über unternehmergewinn, kapital, kredit, zins und den konjunkturzyklus. Berlin: Duncker \& Humblot. Siebente Auflage - 1987. 
Schumpeter, J. (1943). Capitalism, social and democracy. U.S.A.: Routledge Taylor \& Francis e-Library - 2003.

SIRE - Social Innovation Research European (2013). Social frontiers: the next edge of social innovation research. Disponible en: http://siresearch.eu/event/social-frontiers-next-edge-socialinnovation-research

Suddaby, R. (2010). Editor's comments: construct clarity in theories of management and organization. En: Academy of Management Review, 35(3): 346-357.

Touraine, A. (1997). ¿Podremos vivir juntos? Argentina: Fondo de Cultura Económica.
Touraine, A. (2001). ¿Qué es la democracia? México: Fondo de Cultura Económica.

Von Hippel, E. (1988). The sources of innovation. Oxford: Oxford University Press

Wheatley, M. \& Frieze, D. (2006). Using emergence to take social innovation to scale. Provo, UT.: The Berkana Institute. Disponible en:http://berkana.org/wp-content/uploads/2011/09/ Emergence.pdf

Young, I. (1989). Polity and group difference: a critique of the ideal of universal citizenship. En: Ethics, 99(2): 250-274. 